\title{
Thyroid Cancers: From Surgery to Current and Future Systemic Therapies through Their Molecular Identities
}

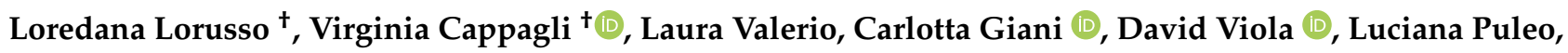 \\ Carla Gambale, Elisa Minaldi, Maria Cristina Campopiano, Antonio Matrone, Valeria Bottici, Laura Agate, \\ Eleonora Molinaro and Rossella Elisei * (1)
}

check for updates

Citation: Lorusso, L.; Cappagli, V.; Valerio, L.; Giani, C.; Viola, D.; Puleo, L.; Gambale, C.; Minaldi, E.; Campopiano, M.C.; Matrone, A.; et al. Thyroid Cancers: From Surgery to Current and Future Systemic Therapies through Their Molecular Identities. Int. J. Mol. Sci. 2021, 22, 3117. https://doi.org/10.3390/ ijms22063117

Academic Editor: Daniela Grimm

Received: 10 February 2021

Accepted: 10 March 2021

Published: 18 March 2021

Publisher's Note: MDPI stays neutral with regard to jurisdictional claims in published maps and institutional affiliations.

Copyright: (c) 2021 by the authors. Licensee MDPI, Basel, Switzerland. This article is an open access article distributed under the terms and conditions of the Creative Commons Attribution (CC BY) license (https:/ / creativecommons.org/licenses/by/ $4.0 /)$.
Endocrine Unit, Department of Clinical and Experimental Medicine, University of Pisa, 56126 Pisa, Italy; lorussoloredana@hotmail.it (L.L.); virgicap@hotmail.com (V.C.); lau.val@hotmail.it (L.V.); carlottagiani@hotmail.com (C.G.); violadavid@hotmail.it (D.V.); puleo.luciana@gmail.com (L.P.); gambalecarla@libero.it (C.G.); elisaminaldi@hotmail.it (E.M.); cristina.campopiano@gmail.com (M.C.C.); anto.matrone@yahoo.com (A.M.); valeriabottici@gmail.com (V.B.); laura.agate@virgilio.it (L.A.); elemoli@hotmail.com (E.M.)

* Correspondence: rossella.elisei@med.unipi.it; Tel.: +39-050-995120; Fax: +39-050-578772

+ Both authors equally contributed to the manuscript.

Abstract: Differentiated thyroid cancers (DTC) are commonly and successfully treated with total thyroidectomy plus/minus radioiodine therapy (RAI). Medullary thyroid cancer (MTC) is only treated with surgery but only intrathyroidal tumors are cured. The worst prognosis is for anaplastic (ATC) and poorly differentiated thyroid cancer (PDTC). Whenever a local or metastatic advanced disease is present, other treatments are required, varying from local to systemic therapies. In the last decade, the efficacy of the targeted therapies and, in particular, tyrosine kinase inhibitors (TKIs) has been demonstrated. They can prolong the disease progression-free survival and represent the most important therapeutic option for the treatment of advanced and progressive thyroid cancer. Currently, lenvatinib and sorafenib are the approved drugs for the treatment of RAI-refractory DTC and PDTC while advanced MTC can be treated with either cabozantinib or vandetanib. Dabrafenib plus trametinib is the only approved treatment by FDA for $B R A F^{V 600 E}$ mutated ATC. A new generation of TKIs, specifically for single altered oncogenes, is under evaluation in phase 2 and 3 clinical trials. The aim of this review was to provide an overview of the current and future treatments of thyroid cancer with regards to the advanced and progressive cases that require systemic therapies that are becoming more and more targeted on the molecular identity of the tumor.

Keywords: differentiated thyroid cancer; medullary thyroid cancer; targeted therapy; tyrosine kinase inhibitors; sorafenib; lenvatinib; vandetanib; cabozantinib; selpercatinib; pralsetinib

\section{Introduction}

Thyroid cancer (TC) is the most common endocrine neoplasia and represents approximately $2.9 \%$ of all new cancer cases in the United States each year [1]. In the last three decades, the incidence rate of TC has continuously increased all over the world and, although it was mainly attributed to an increased detection rate of small tumors, a real increase of TC was also identified as demonstrated by an increase of larger tumors too [2]. In this review, we discuss the different types of current and future systemic therapies to be used in different types of advanced and metastatic TC. A brief description of the different histotypes of TC and signaling pathways is required to better understand the different types of targeted therapies available.

\subsection{Differentiated Thyroid Cancer}

Differentiated thyroid cancer (DTC) is the most frequent tumor type, representing $>90 \%$ of all TC [3]. It originates from follicular cells and includes the three main subtypes: 
papillary (PTC), follicular (FTC), and Hürthle cell carcinoma (HTC). Despite the overall survival (OS) rate being $98.3 \%$ at 5 years for the majority of cases [1], local recurrence (thyroid bed or cervical lymph nodes) occurs in about $20 \%$ of patients and distant metastasis in approximately $10 \%$, lungs being the most common site of metastases (50\%) followed by bone (25\%) [4]. In one third of advanced DTC, the metastatic lesions lose the ability to take up iodine (RAI-refractory DTC) with subsequently no efficacy of radioiodine with ${ }^{131}$ I (RAI) and decrease of OS rate (less than $10 \%$ at 10 years) [5]. As well as RAI-refractoriness, the stage of neoplastic disease at diagnosis can also predict mortality. In particular, according to the 8th Edition of the American Joint Committee on Cancer TNM classification [6], an excellent prognosis is reported for stage I and II of DTC with an overall disease-specific survival of $>75 \%$ to $95 \%$ at 10 years that falls to $60 \%$ to $<50 \%$ for stage III and IV, respectively.

Poorly differentiated thyroid cancer (PDTC) is a heterogeneous group that includes those TCs that, according to the Turin classification, lose the papillary nuclear features and have a solid, insular, or trabecular growth pattern with an increased number of mitoses and necrosis [7,8]. PDTC in respect with other DTCs has a higher risk of persistence/recurrence both in the neck and at distant localization (lung, liver, bone, and brain) and a higher mortality $[9,10]$.

According to the most recent guidelines [11], the gold standard of treatment for DTC and PDTC is represented by surgery (total or near-total thyroidectomy). Before cervical surgery, an accurate ultrasound evaluation of neck and mediastinum should be performed in all patients to identify lymphadenopathy that should be surgically removed simultaneously with the thyroid. Patients with intermediate or high risk of recurrent disease or with distant metastases should be treated with a subsequent ${ }^{131}$ I therapy and thyroid stimulating hormone (TSH) suppressive therapy [11].

For patients with metastatic DTC that progresses despite standard therapies, systemic cytotoxic chemotherapy has been evaluated both in phase 2 and retrospective studies but, to date, there is no role for its routinary use. Doxorubicin (recommended dosage: $60-75 \mathrm{mg} / \mathrm{m}^{2}$ every 3 weeks) remains the single most effective and approved cytotoxic chemotherapy for the treatment of RAI-refractory DTC patients with metastatic, rapidly progressive, symptomatic, and/or imminently threatening disease but it should be used only when cases are not manageable with other approaches. Nowadays, as described in following paragraphs, targeted therapies able to inhibit abnormal activated tyrosine kinases (TKI) represent the systemic therapies that should be used as first line in metastatic TCs.

Regarding adjuvant neck/thyroid bed/locoregional external beam radiation (EBRT), its application in DTC/PDTC patients remains controversial and, according to the literature, there is no role for routine adjuvant EBRT to the neck in DTC patients, especially when an initial complete surgical removal of the tumor is achieved. However, EBRT should be considered for those patients undergoing multiple and frequent neck re-operations for palliation of locoregional recurrences and, in some cases of bone metastases especially to control the pain that is frequently associated with these lesions. [12,13].

Recently, several studies have reported the efficacy of other localized treatments with thermal (radiofrequency or cryo-) ablation [14,15], ethanol ablation [16,17], or chemoembolization [18] on single/few metastases or on locoregional persistence/recurrence of neoplastic disease. These kinds of treatments can be offered to those patients with high risk for surgery, those who refuse to undergo repeated surgeries, and those with oligometastatic but progressing disease. The possibility of performing these localized treatments should always be taken into consideration before the initiation of systemic treatment [11].

\subsection{Anaplastic Thyroid Cancer}

Anaplastic thyroid carcinoma (ATC) represents about $1 \%$ of all TC and is the most aggressive thyroid tumor, accounting for the majority of all TC death [19]. The ATC is a rare undifferentiated form of TC, unable to take up ${ }^{131}$ I and with no chance of cure $[19,20]$. It is associated with a rapid and lethal progression, especially at a local level. At the time of diagnosis, $30-40 \%$ of patients have locoregional metastases and/or vocal cord paralysis 
and $70 \%$ have direct invasion of local tissue including the trachea, muscle, esophagus, and larynx. Distant metastasis usually appears in those patients receiving aggressive treatments and can involve multiple sites including the lungs (50-80\%), bone, skin, and brain (6-12\%) [21]. Median survival time in ATC patients is approximately 5-6 months, and only $10-15 \%$ of patients survive 2 years after presentation $[19,21]$. Due to this fatal outcome, TNM classification of the American Joint Committee on Cancer provides only stage IV for this tumor, which can be subdivided into IVA when the tumor is confined to the thyroid, IVB when the tumor is present beyond the thyroid gland but confined in the neck, and IVC when distant metastases are present.

The initial management of ATC should include the evaluation of airways' stability to establish whether an immediate intervention is necessary, and the evaluation of full resectability (R0) of primary tumor, since the only debulking of the cancer does not improve the patient's outcome. Therefore, surgery should be of first choice when a full resection of tumor can be obtained and when no distant metastases are identified. About 2 to 4 weeks after surgery, chemoradiation should be offered to the patient, while unresectable ATC should be treated directly with radiation therapy ( $\geq 60 \mathrm{~Gy}$ on primary tumor) and adjuvant chemotherapy. Standard cytotoxic chemotherapy includes taxane, platinum-based drugs, and doxorubicin [22].

The same approach (radiation therapy and chemotherapy without local surgery) should also be offered to those patients with small-volume metastases while systemic therapies with or without palliative radiation therapy should be considered in patients with large-volume metastases. Nowadays, only specific TKI can be used in restricted subgroups of ATC with specific molecular alterations such as BRAF ${ }^{V 600 E}$ mutations, RET or TRK fusions as discussed below.

\subsection{Medullary Thyroid Cancer}

Medullary thyroid cancer (MTC) originates from neural crest $C$ cells and represents $4 \%$ of all TC. The biological behavior of MTC is more severe than that of DTC: the 10-years survival rate is approximately $50 \%$ and can be lower in patients with advanced disease at diagnosis [23]. Distant metastases are observed at presentation in $7-23 \%$ of MTC patients and are the main cause of MTC-related death. Total thyroidectomy and central compartment neck dissection is the primary surgical treatment and the only curative one for localized MTC. When a widespread regional or metastatic disease is present, repeated surgeries are not associated with a higher cure rate, and less aggressive procedures should be considered. In these cases, whenever possible, according to the extension and the sites of the disease, a local treatment should be preferred while systemic therapy should be used when the disease becomes multimetastatic and rapidly progressive [24,25]. EBRT is indicated to improve the local control of disease in case of local recurrence or locoregional lymph node metastases or as palliative therapy to reduce pain from bone metastases or to treat brain metastases [25]. Radiofrequency thermo-ablation is frequently applicable to bone, liver, and lung to treat single metastases or a single progressive and symptomatic one in the context of a stable disease [26,27]. Another quite new and promising local treatment is the conventional transarterial chemoembolization (TACE) or radioembolization (TARE) commonly used in some advanced cases of liver metastatic disease, especially when liver metastases are smaller than $3 \mathrm{~cm}$ and the liver involvement is less than 30\% [28]. Among systemic therapy, chemotherapy shows no clinical durable advantages and benefits in MTC and for this reason is no longer indicated [25]. Over the years, several types of radionuclides have been studied for the treatment of MTC, based on its neuroendocrine origin, but despite the decrease of its serum marker (i.e., calcitonin (CT)), no results have been obtained in terms of reduction of size and number of metastatic lesions [29]. Recently, promising results have been shown for the peptide receptor radionuclide therapy using 177Lu-labeled or 90Y-labeled somatostatin analogues, but it is limited to MTC cases with significant somatostatin receptors expression [30]. 
Nowadays, the current systemic options for the treatment of advanced and progressive MTC are both multi-targeted and specific TKI as we will describe thereafter.

\section{Intracellular Signaling Pathways in Thyroid Cancer}

In the last decades, the mutations identified by several studies and by the Cancer Genome Atlas (TCGA) show different patterns mostly affecting two signaling pathways: mitogen-activated protein kinase (MAPK) and phosphatidylinositol-3 kinase (PI3K) pathways [31-33] (Figure 1). When a mutation at any level of these pathways occurs, resulting from a somatic or germline genetic alteration of the transmembrane receptors (TKR) or from a central mediator, the signaling becomes constitutively activated, causing an uncontrolled cell replication, loss of cell differentiation, and decrease of cell apoptosis. Both genetic and epigenetic modifications in pathway receptors and effectors are involved [34], and promote the progression of follicular thyroid cells to PTC or FTC. Additional mutations and/or rearrangements and an increase of the MAPK and/or PI3K pathways signaling seem to promote a further progression to PDTC, while further genetic events, especially involving $p 53$, epigenetic alteration, and infiltration of immune cells, lead to the onset of ATC (Figure 2).

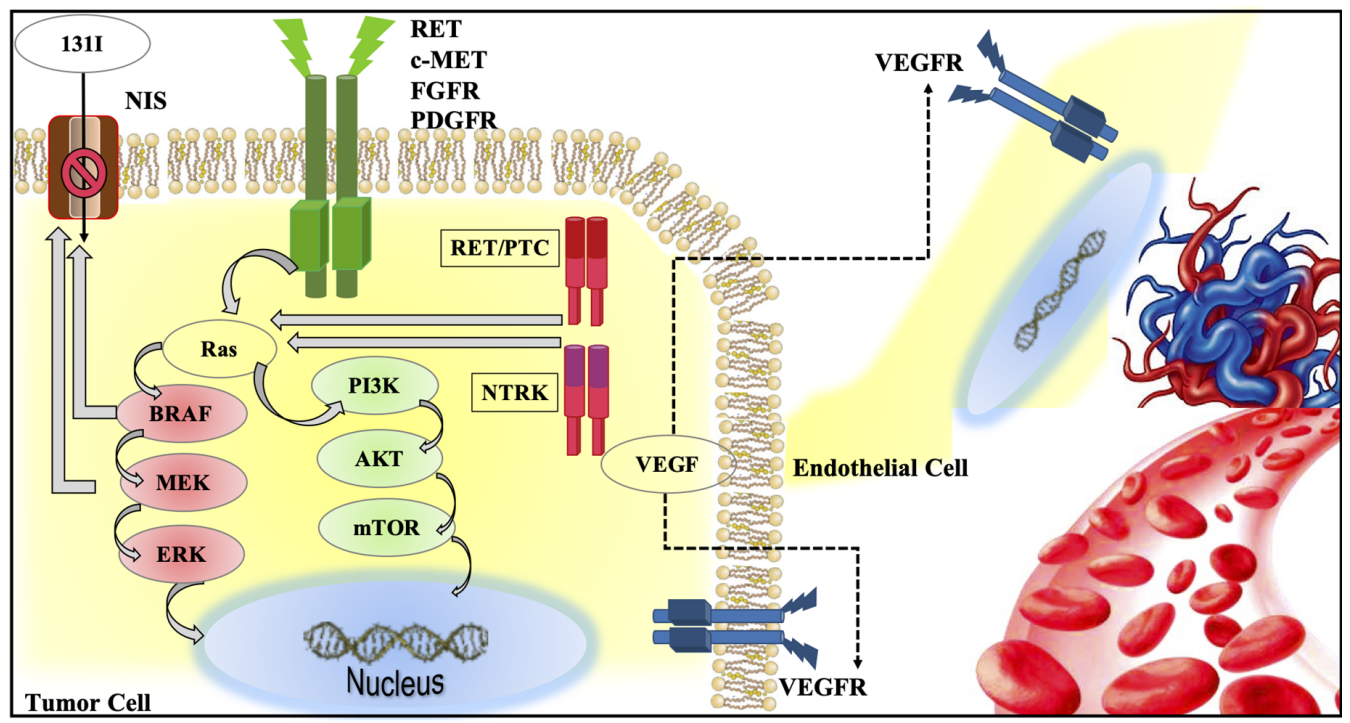

Figure 1. Graphic representation of intracellular pathways (i.e., mitogen-activated protein kinase (MAPK) and phosphoinositide-3-kinase (PI3K)), activated by tyrosine kinase receptors (i.e., RET, MET, FGFR, PDGFR) in thyroid cancer. Activation of $B R A F$ and $M E K$ also play an important role in the loss of sodium iodide symporter (NIS) activity, leading to RAI refractoriness. The vascular endothelial growth factor receptor is present on the cellular membrane of both tumor and endothelial cells and it is the major player of the new tumor angiogenesis. 


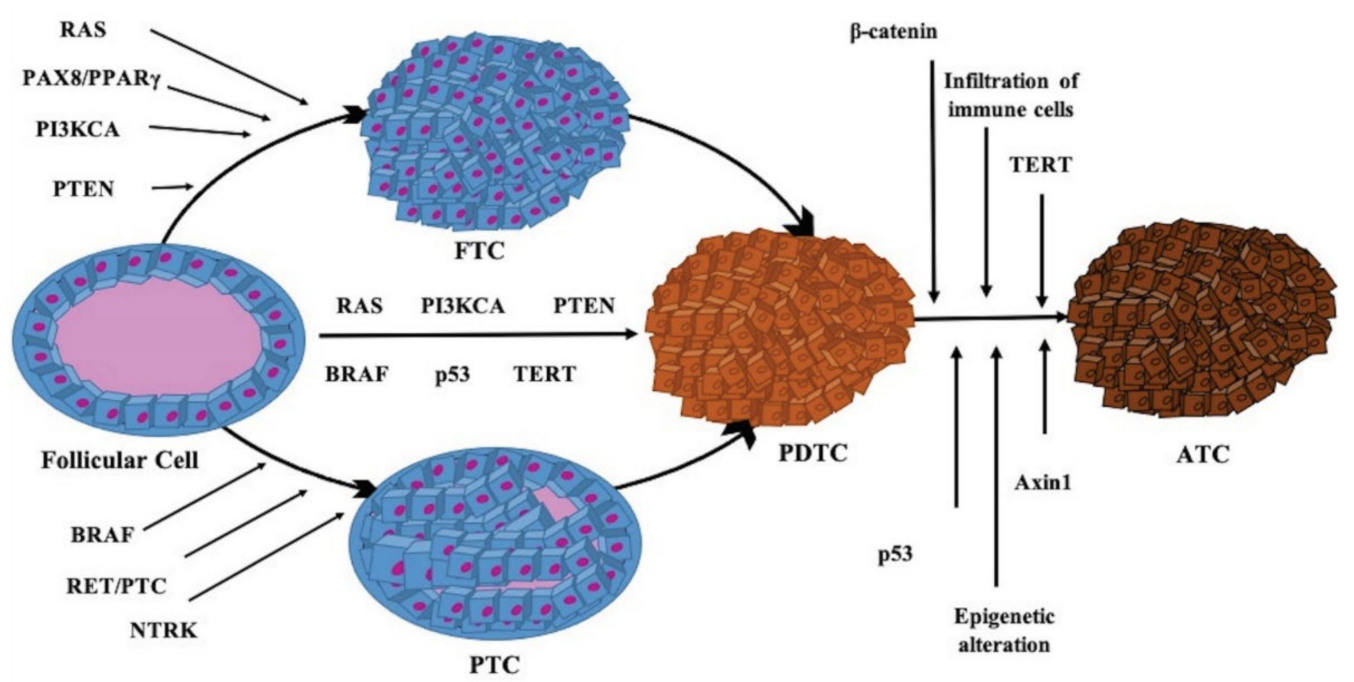

Figure 2. Molecular alterations that lead to mitogen-activated protein kinase (MAPK), phosphoinositide-3-kinase (PI3K), and receptor kinase pathways activation and promote the progression of follicular thyroid cells to papillary (PTC) and to follicular thyroid cancer (FTC). Additional mutations and rearrangements and an increase of MAPK and PI3K pathways signaling promote further progression to poorly differentiated thyroid cancer (PDTC). Further genetic events, especially involving p53, epigenetic alteration, and infiltration of immune cells, promote the onset of anaplastic thyroid cancer (ATC).

\subsection{MAPK and PI3K Pathways}

The most common genetic alterations in TC associated with MAPK and PI3K signaling pathways include mutations in central mediators such as $B R A F, R A S, P T E N, A K T$, and PI3KCA (Figure 2).

$B R A F^{V 600 E}$ is the most common mutation in PTC. It was described in $18-87 \%$ of PTCs and, less frequently, in PDTC, ATC, and HTC [35,36], and it is mutually exclusive with other mutations, thus suggesting that the presence of one single driver mutation is sufficient for thyroid tumorigenesis [37]. BRAF ${ }^{V 600 E}$ mutations, as well as oncogenic activation of MEK/ERK, also play an important role in the loss of sodium iodide symporter (NIS) activity, leading to RAI refractoriness [38].

RAS mutations are reported in $30-40 \%$ of FTC, in $30-45 \%$ of follicular variant PTC (rarely in classical variant of PTC), in 15\% of HTC, in $20-40 \%$ of PDTC and ATC, and in $10-30 \%$ of MTC [39-42].

Although their frequency is low [43], PTEN, AKT, and PIK3CA are the most common mutated mediators in PI3K pathways. Mutations, deletions, and epigenetic changes of oncosuppressor PTEN were described in DTC, PDTC, ATC, and HTC [33,35,42]. AKT1, $A K T 2$, and $A K T 3$ were reported in very few cases of TC and some $A K T 1$ mutations were reported in ATC and in FTC [44] and in a TC metastasis, suggesting that this mutation can occur late during cancer progression [45]. As well as for AKT1, PIK3CA amplifications, and less commonly mutations, were observed late in TC progression and more frequently in ATC than DTC $[45,46]$.

RET proto-oncogene is one of the most common altered oncogene coding for a TKR in TC [47]. As well as its occurrence in other altered central mediators, when a mutation occurred in RET, this oncogene became constitutively activated with a subsequent activation of MAPK and PI3K pathways [42]. In PTC, the most prevalent RET alterations are RET/PTC rearrangements. In particular, a RET fusion was found in about $50 \%$ of PTC diagnosed in atomic bomb survivors after a high radiation dose exposure and was very common, especially RET/PTC1 and RET/PTC3, in childhood TC diagnosed after the Chernobyl accident $[48,49]$. 
In MTC, the most common genetic alterations are the RET oncogene gain of function point mutations, both in sporadic MTC cases, in which a somatic RET mutation is found in about $40-70 \%$ of patients, and in familiar/hereditary MTC cases, in which a germline mutation is present in $95 \%$ of kindred [50]. The most frequent RET point mutation detected in multiple endocrine neoplasia syndrome (MEN) type $2 \mathrm{~A}$ occurs on codon 634 , while in $95 \%$ of MEN 2B and in 75-95\% of sporadic cases the most frequent alteration is RET mutation M918T [51,52]. Different RET mutations produce distinct phenotypes that can differ in terms of age of onset of MTC, aggressiveness of MTC, and association with other endocrine malignancies [51].

Neurothrophic receptor tyrosine kinase (NTRK) are a group of tyrosine kinase (TK) receptors encoded by the NTRK1, NTRK2, and NTRK3 genes and their rearrangements were reported in PTC, PDTC, and ATC $[33,53,54]$. Due to a phosphorylation of their tyrosine residues, mutated receptors, encoded by mutated NTRK, lead to constitutive activation of MAPK, PI3K, and phospholipase C-signaling pathways [53,54], acting as oncogenic drivers.

Mutations and gene fusions involving anaplastic lymphoma kinase $(A L K)$ were also reported, mainly in PDTC and ATC and less frequently in PTC $[42,55,56]$. In particular, in ATC two different mutations with aminoacidic changes within ALK TK domain were identified [57].

Growing evidence has revealed the importance of tumor microenvironment, composed of the extracellular matrix and stromal cells. Indeed, with relevant changes in microenvironment, tumors become able to survive, grow, invade, and give distant metastasis and the improvement of angiogenesis is the most important process reported [58,59].

\subsection{Other Genetic Alteration in Thyroid Cancer}

In about $30-35 \%$ of FTC but also in follicular variant of PTC (FVPTC), PAX8/PPAR $\gamma$ rearrangement is reported. The $P A X 8 / P P A R \gamma$ gene fusion results in the production of an oncoprotein, PAX8/PPAR- $\gamma$ fusion protein, that is considered to act as a dominant-negative inhibitor of wild-type PPAR $\gamma$ and/or as a unique transcriptional activator of subsets of PPAR $\gamma$-responsive and PAX8-responsive genes [60,61].

In $50-80 \%$ of ATC and in up to $35 \%$ of PDTC, mutations of oncosuppressor TP53 are described. The same alteration can also be found in the most aggressive FTC and PTC $[42,62]$. Other common mutations in ATC and PDTC regard Wnt- pathways, including the gain of function mutation of $\beta$-catenin gene and the loss of function mutation of Axin 1 gene $[63,64]$.

Another mutation frequently found in ATC (40-70\%) and in PDTC (40\%) involves TERT promoter. The same promoter alterations can also be found in the aggressive forms of HTC, PTC, and FTC $[42,65]$.

\subsection{Immune Microenvironment}

The immune system is the major determinant of tumor microenvironment. Many studies have shown that the escape from immune response called "tumor immunoediting" has a role in thyroid tumor progression and that immune cells, both from adaptive (T cells) and innate system (macrophage), secreted soluble mediators, and immune checkpoints are the principal mediators in this scenario [66]. More in details, T regulatory lymphocytes are highly expressed in the tumor microenvironment, where they exert an immunosuppressive function and are associated with a poorer prognosis [67]. The $\mathrm{CD} 4^{+} \mathrm{CD} 25^{+} \mathrm{T}$ cells were demonstrated to be more expressed in PTC than in benign thyroid nodules and were associated with PTC invasiveness [68]. Cytotoxic T cells are, on the contrary, specialized in killing target cells and are involved in promoting tumor cells apoptosis and cellular proliferation inhibition [67]. In PTC, low cytotoxic T cells concentration was associated with bigger and more invasive tumors [69]. Tumor-associated macrophages (TAM) are the most abundant cells in tumor-infiltrate and their products that are modulated by cancer cells, are able to remodel extracellular matrix, facilitate angiogenesis, and promote tumor cell migration and invasion [70,71]. In TC, particularly in PTC, higher expression levels of 
TAM in tumor microenvironment were associated with lymph node metastases and poorer prognosis [72].

Immune checkpoints are regulators of $\mathrm{T}$ cells immune response through co-stimulatory or inhibitory molecules: cytotoxic T lymphocyte antigen4 (CTLA-4), programmed cell death protein 1 (PD-1), programmed cell death protein 1 ligand (PD-L1) inhibit the T cells mediated control on tumor cells proliferation. In TC, PDL-1 was differently expressed according to the hystotype, with higher expression levels in ATC (822.25) with respect to FTC (7.6\%) and PTC (6.1\%), with even higher expression in advanced TC [73]. In PTC, higher expression of CTLA-4 and PD-L1 was associated with $B R A F^{V 600 E}$ mutation and a lower degree of differentiation [74]. On the contrary, in most studies PD-L1 expression was almost negative in MTC [75]. Based on this data, two main immunotherapy strategies have been designed: one increasing the ability of body cells to kill tumoral ones (i.e., tumor vaccines and adoptive cells therapy) and the other one improving the ability of immune cells to suppress tumor development (i.e., immune checkpoint inhibitors).

\section{Current Available Systemic Therapies for the Treatment of Advanced and Multimetastatic Thyroid Cancer}

Over the last decades, several small molecular agents able to inhibit TK and TKR with different mechanisms have been generated and have been demonstrated to be effective anti-solid tumor and anti-leukemic agents with the name of TKIs. This first generation of TKIs are able to inhibit specific oncogene alterations but they also act against several other TKRs and for this reason they are also recognized as multikinase inhibitors (MKI). Sometimes, the activity of these MKI against these other receptors is stronger than the activity they have against the driver oncogene alteration of TC, and several adverse events (AEs) are due to these "off-targeted" activities.

Four MKI, lenvatinib and sorafenib for the treatment of advanced RAI-refractory DTC, and vandetanib and cabozantinib for the treatment of MTC, have lastly been approved by both the Food and Drug Administration (FDA) and the European Medical Agency (EMA).

Recently, a second generation of TKIs has been developed which are specific for a specific altered oncogene. The high specificity of these drugs is the reason for a greater tolerability because of a much smaller number of AEs having very few "off-targeted" activities.

So far, four of them, larotrectinib, entrectinib, selpercatinib, and pralsetinib have been approved by FDA and are under evaluation of EMA.

\subsection{Systemic Treatment in DTC and PDTC: Multikinase Inhibitor Approved Drugs}

Sorafenib is a small oral molecule with a strong anti-angiogenic activity. Sorafenib is able to inhibit VEGF1-3, PDGF, FGF, KIT, RET receptors and, weakly, RAF (Table 1). After two different phase 2 trials $[76,77]$ that demonstrated its efficacy in DTC patients, a randomized, double-blinded, placebo-controlled phase 3 trial (DECISION study) [78] was designed. In DECISION study, 207 patients were randomized to the drug and received a starting dose of $400 \mathrm{mg}$ twice a day, while 209 patients were randomized to placebo. A crossover from placebo to drug was available when a disease progression was demonstrated in placebo patients after they were unblinded. All 417 patients were TKI naïve. The primary endpoint was the evaluation of progression-free survival (PFS) that was significantly longer in sorafenib-group than in placebo-group (10.8 months and 5.8 months, respectively; $p<0.0001$ ) with a response rate of $12.2 \%$ in the first group and of $0.5 \%$ in the second one. OS was not different in the two groups, but this was probably due to the crossover from placebo to sorafenib. Table 2 shows the most common side effects of the drug. 
Table 1. Molecular targets of currently available tyrosine kinase inhibitors.

\begin{tabular}{|c|c|c|c|c|c|c|c|c|c|}
\hline $\begin{array}{c}\text { Drugs/ } \\
\text { Clinical Trials }\end{array}$ & VEGFR-1 & VEGFR-2 & VEGFR-3 & c-KIT & RET & PDGFR & FGFR & EGFR & Others \\
\hline $\begin{array}{c}\text { Lenvatinib } \\
\text { (Schlumberger et al.) }\end{array}$ & + & + & + & + & + & + & + & - & $\begin{array}{c}\text { RET-KIF5B } \\
\text { rearrangements }\end{array}$ \\
\hline $\begin{array}{c}\text { Sorafenib } \\
\text { (Brose et al.) }\end{array}$ & - & + & + & + & + & + & - & - & Raf, FLT3 \\
\hline $\begin{array}{l}\text { Vandetanib } \\
\text { (Wells et al.) }\end{array}$ & - & + & - & + & + & - & - & + & $\begin{array}{c}\text { RET-KIF5B } \\
\text { rearrangements }\end{array}$ \\
\hline $\begin{array}{l}\text { Cabozantinib } \\
\text { (Elisei et al.) }\end{array}$ & - & + & - & + & + & - & - & - & $\begin{array}{c}\text { MET, RET-KIF5B } \\
\text { rearrangements }\end{array}$ \\
\hline $\begin{array}{l}\text { Larotrectinib } \\
\text { (Drilon et al.) }\end{array}$ & - & - & - & - & - & - & - & - & TRK1 \\
\hline $\begin{array}{c}\text { Entrectinib } \\
\text { (Doebele et al.) }\end{array}$ & - & - & - & - & - & - & - & - & TRK, ALK, ROS1 \\
\hline $\begin{array}{l}\text { Selpercatinib } \\
\text { (Wirth et al.) }\end{array}$ & - & - & - & - & + & - & - & - & - \\
\hline $\begin{array}{c}\text { Pralsetinib } \\
\text { (NCT03037385) }\end{array}$ & - & - & - & - & + & - & - & - & - \\
\hline $\begin{array}{c}\text { Vemurafenib } \\
\text { (Brose et al.) } \\
\text { (Hytman et al.) }\end{array}$ & - & - & - & - & - & - & - & - & BRAFV600E \\
\hline $\begin{array}{c}\text { Dabrafenib } \\
\text { (Falchook et al.) }\end{array}$ & - & - & - & - & - & - & - & - & BRAFV600E \\
\hline
\end{tabular}

Table 2. More frequent adverse events reported for the currently available tyrosine kinase inhibitors.

\begin{tabular}{|c|c|c|c|c|c|c|c|c|}
\hline $\begin{array}{l}\text { Adverse Events } \\
\text { (All Grade) }\end{array}$ & $\begin{array}{l}\text { Lenvatinib } \\
\quad(\%)\end{array}$ & $\begin{array}{l}\text { Sorafenib } \\
\quad(\%)\end{array}$ & $\begin{array}{c}\text { Vandetanib } \\
(\%)\end{array}$ & $\begin{array}{c}\text { Cabozantinib } \\
(\%)\end{array}$ & $\begin{array}{l}\text { Selpercatinib } \\
(\%)\end{array}$ & $\begin{array}{l}\text { Pralsetinib } \\
\quad(\%)\end{array}$ & $\begin{array}{l}\text { Larotrectinib } \\
(\%)\end{array}$ & $\begin{array}{c}\text { Entrectinib } \\
(\%)\end{array}$ \\
\hline Hypertension & 68 & 41 & 32 & 33 & 43 & 40 & 11 & NR \\
\hline Diarrhea & 59 & 69 & 56 & 63 & 38 & 34 & 22 & 35 \\
\hline Skin rash & 15 & 50 & 45 & 19 & NR & $24 *$ & NR & 11 \\
\hline Anorexia & 49 & 32 & 21 & 46 & NR & 15 & 13 & 13 \\
\hline Fatigue & 59 & 50 & 24 & 41 & 38 & 38 & 37 & 48 \\
\hline Nausea & 41 & 20 & 33 & 43 & 35 & 17 & 29 & 34 \\
\hline Weight loss & 46 & 47 & 10 & 48 & NR & NR & NR & NR \\
\hline QT prolongation & 8 & NR & 14 & NR & 19 & NR & NR & 3.1 \\
\hline Hand-foot syndrome & 32 & 76 & NR & 50 & NR & NR & NR & NR \\
\hline Weight gain & NR & NR & NR & NR & 25 & NR & 15 & 25 \\
\hline $\begin{array}{l}\text { Increased aspartate } \\
\text { aminotransferase level }\end{array}$ & $0.4^{* *}$ & 23 & NR & 86 & 57 & 69 & 45 & 44 \\
\hline $\begin{array}{c}\text { Increased alanine } \\
\text { aminotransferase level }\end{array}$ & $0.4^{* *}$ & 26 & NR & 86 & 51 & 43 & 45 & 38 \\
\hline
\end{tabular}

Abbreviations: NR: not reported. * Rash includes dermatitis, dermatitis acneiform, eczema, palmar-plantar, erythrodysaesthesia syndrome, rash, rash erythematous, rash macular, rash maculo-papular, rash papular, rash pustular. ${ }^{* *}$ This percentage, the only reported in the drug-related study, is referred only to serious adverse events.

Initially approved for renal and hepatocellular carcinoma, DECISION study led to the approval of sorafenib for the treatment of ${ }^{131}$ I refractory DTC. 
Since the response rate appeared to be low $(12.2 \%)$ when sorafenib was used as a single-agent, a phase 2 study [79] was started to determine whether adding temsirolimus, an inhibitor of mammalian targeted of rapamycin (mTOR), to sorafenib could improve these results. Thirty-six patients with metastatic, RAI-refractory TC of follicular origin received treatment with the combination of oral sorafenib (200 mg twice daily) and intravenous temsirolimus (25 mg weekly). The best response was a partial response (PR) in $58 \%$, and progressive disease (PD) in 3\% (six patients were not evaluable for a response). Response rate was $10 \%$ in patients who had received any prior systemic treatment and $38 \%$ in those who had not received prior systemic treatment. One of two patients with ATC had an objective response. PFS at 1 year was $30.5 \%$. The most common grade 3 and 4 toxicities were hyperglycemia, fatigue, anemia, and oral mucositis.

Sorafenib was also administered in a phase 2 study [80] in patients with ATC on the basis that the BRAF oncogene is mutated to its active form in up to $24 \%$ of ATC cases. Twenty ATC patients were enrolled and sorafenib was administered at $400 \mathrm{mg}$ twice daily. The evaluation of the disease by RECIST revealed $10 \%$ of PR and $25 \%$ of stable disease (SD). The duration of response in the two responders was 10 and 27 months, respectively. For the patients with SD, the median duration was 4 months (range 3-11 months). The overall median PFS was 1.9 months with a median and a 1-year survival of 3.9 months and $20 \%$, respectively. Furthermore, in this study, toxicity was manageable and as previously described for sorafenib, included hypertension and skin rash. The authors concluded that, although sorafenib has activity in ATC, this is at a low frequency and is similar to the previous experience with fosbretabulin [81].

Lenvatinib, as well as sorafenib, is an oral TKI with a high anti-angiogenic activity. Lenvatinib is able to inhibit VEGF1-3, FGF1-4, PDGF, KIT, and RET receptors (Table 1). The efficacy of lenvatinib in TC, both DTC and MTC, was first demonstrated in a phase 2 study [82], and, then, a multicentric, randomized, placebo-controlled phase 3 study was designed (SELECT study) [83]. A total of 392 patients were enrolled in the study and, in particular, 261 were randomized in lenvatinib arm, starting with $24 \mathrm{mg} /$ day of drug, and 131 patients in placebo arm. Patients who received, before the enrolment, a previous treatment with no more than one TKI were allowed. The primary endpoint was the evaluation of PFS that was significantly longer in lenvatinib-group than in placebogroup (18.3 months and 3.6 months, respectively; $p<0.001$ ) with 4 complete responses $(C R)$ in lenvatinib-group. A sub-analysis confirmed that PFS was also longer in lenvatinib-group when patients receiving a previous TKI therapy were considered. Although OS was not different in the two groups, when a sub-analysis stratified the patients by age, an OS advantage in patients older than 65 years old was demonstrated. Table 2 shows the most common side effects of this drug. No unexpected toxicities were reported.

A post-marketing multicenter, randomized, double-blind phase 2 study was conducted to evaluate if a lower starting dose could demonstrate the same clinical benefits with a lower AEs incidence (Study 311, NCT02702388). The study is still active but is no longer recruiting and 152 participants have been enrolled. They were randomly assigned to treatment with 1 of 2 blinded dosages of lenvatinib in a 1:1 ratio to receive lenvatinib $18 \mathrm{mg}$ or $24 \mathrm{mg}$ orally once daily. The estimated study completion date was September 2020 and, even if the full results have not yet been presented, in a press release from EISAI company topline the results were shown. According to these results, the $18 \mathrm{mg}$ dose did not show non-inferiority in efficacy in respect with the $24 \mathrm{mg}$ dose as measured by ORR at week 24, and the incidences of grade 3 or higher treatment-emergent AEs through week 24 were similar between dose arms.

Before and after the commercialization of the drug, several studies were published about the real-life use of the drug showing the same safety results with a lower PFS [84,85]. An expanded access program (EAP) was also initiated in Italy to evaluate the drug's safety compared to the SELECT study and other series and patients' quality of life [86]. In this study, all AEs that occurred during the 6 months of lenvatinib treatment in 39 RAI-DTC patients were recorded. According to these results, the safety profile of lenvatinib was 
similar to that already reported in other studies with differences in percentages and grading: a lower percentage of patients experienced diarrhea (36.1\%), weight loss $(30.5 \%)$, nausea $(11.1 \%)$, and proteinuria $(11.15 \%)$. Regarding the evaluation of quality of life, the EAP study showed a trend of improvement of the general health status and a reduction of symptoms correlated to the disease.

Lenvatinib was also demonstrated to be effective in a retrospective, single center analysis of 18 Korean patients with confirmed ATC [87]. Six patients had resectable disease that progressed after a combination of surgery, radiotherapy, and chemotherapy, and 12 had unresectable disease that progressed after radiation treatment and chemotherapy. Median OS for the 18 lenvatinib-treated patients was 230 days while the survival rates at 6 months and 1 year were $61.1 \%$ and $22.2 \%$, respectively. Three patients survived beyond 1 year; 15 patients died, of whom four had local disease and 11 had distant metastasis. Two patients had tumor volume increases of $9-10 \%$. The other 16 patients had tumor volume reductions of $2-69 \%$. Six patients had tumor volume reduction $\geq 50 \%$. Similar results in ATC patients were obtained in a previous study of Takahashi et al. [88].

To date, lenvatinib is approved for the treatment of RAI refractory DTC, hepatocellular carcinoma, and, in combination with everolimus, for renal cell carcinoma, but not for ATC.

\subsection{Systemic Treatment in MTC: Multikinase Inhibitor Approved Drugs}

Vandetanib is a once-daily oral multitargeted drug with a recommended daily dose of $300 \mathrm{mg} /$ die, additionally adjusted in case of unmanageable toxicity. Its main molecular targets are represented by VEGFR-2, VEGFR3, EGFR, KIT, and RET as shown in Table 1. Vandetanib was the first TKI approved for the treatment of symptomatic, unresectable, locally advanced or metastatic MTC in adult patients, both by FDA (2011) and EMA (2013). The approval of the drug was due to the results of the international, multicentric and randomized against placebo phase 3 trial (ZETA study) showing a significant longer median progression-free survival in treated patients with respect to the placebo ones (30.5 months versus 19.3 months) [89]. Moreover, a significant clinical benefit in treated patients was also demonstrated for objective response rate (ORR) $(p<0.001)$, disease control rate $(p<0.001)$, and biochemical response $(p<0.001)$. The use of this drug was also approved for children with advanced hereditary MTC thanks to the results obtained in a phase 2 clinical trial [90].

The treatment was generally well tolerated, and its side effect profile was similar to that of other TKIs. Table 2 shows the most frequent AEs at any grade [89]. The QT elongation is a drug-specific side effect and potentially life-threatening, occurring in $14 \%$ of treated patients [89].

With the daily use of vandetanib in real life, some retrospective studies were published in order to find predictive factors for a more durable drug response [91,92]: a younger age at the disease diagnosis and enrolment was able to predict a longer and more durable response to vandetanib. A positive correlation was also found between the presence of AEs, any type, and a better response to treatment [91].

Cabozantinib is an oral multiple TKI approved by the FDA in 2012 and EMA in 2014 for the treatment of progressive and metastatic MTC. It is able to inhibit three main TK receptors: MET, VEGFR2, and RET as shown in Table 1. In the phase 3 clinical trial (EXAM study) a significantly longer median PFS was observed in patients treated with the drug compared to those treated with placebo (11.2 versus 4.0 months) and also a significant difference in the overall response rate corresponding to 28 versus $0 \%$, respectively [93]. Despite these good results, also cabozantinib was not able to improve the OS, except for the subgroup of patients with M918T-RET mutation which showed a significant increase of OS (median survival 44.3 months compared to 18.9 months) [94]. Moreover, cabozantinib seems to also be effective as second-line therapy: in fact, no differences for PFS were observed in the subgroups of naive and previously treated MTC patients and this data could be useful in the real-life management of the drug. 
The most frequent AEs occurring at any grade in the EXAM study are reported in Table 2 [93]. Fatal adverse reactions occurred in 6\% of patients receiving cabozantinib and the death causes were hemorrhage, pneumonia, septicemia, fistulas, cardiac arrest, and respiratory failure. Interestingly, while hemorrhage was present both in the cabozantinib and placebo arm, gastrointestinal perforations (3\%) and fistulas (4\%) were diagnosed exclusively in the cabozantinib arm. No cardiological AEs were observed, in particular no QT elongation was reported.

Another clinical trial with cabozantinib in MTC patients has been conducted and nowadays is still active but no longer recruiting. The randomized, double blind, multicentric EXAMINER clinical study (NCT01896479) has been designed to evaluate two different doses of cabozantinib (60 mg vs. $140 \mathrm{mg}$ ) in progressive and metastatic MTC in order to test if the lower dose has the same results in terms of PFS and overall response rate compared to higher dose but with fewer AEs. According to the study design, previously other TKI treatment was permitted, and patients have been stratified based on M918T-RET status and after randomization they have been treated until disease progression or intolerable toxicity. The study is still ongoing, and no data have been presented so far.

\subsection{Systemic Treatment in DTC, PDTC, and ATC: Specific Inhibitors of NTRK-Fusions}

NTRK fusions are rare but can be found in several solid tumors, including PTC, PDTC, and ATC. When present in TC, this fusion is usually mutually exclusive with other oncogenic driver mutations. Larotrectinib is a highly selective inhibitor of tropomyosin receptor kinase (TRK) A, B, and C (Table 1), and is approved by FDA and EMA for the treatment of all solid cancers that harbor NTRK fusions, both in adult and in pediatric patients. The results of two phase 1 trials and of one phase 2 trial were all together reported in a primary analysis [95] and then in an additional paper with 67 supplemental patients [96]. Supplemental analysis included 109 patients with solid tumors, comprising 19\% of TC. Sixty-three percent of patients had PR (including 10 TC patients) and 17\% a CR (including 3 patients with TC). Recently, an ORR of $79 \%$ and a median duration of response of 35.2 months were reported in patients with TRK fusion cancer in various tumor types treated with larotrectinib [97]. Moreover, at 2020 ESMO meeting, Cabanillas et al. presented the preliminary data on efficacy and safety of larotrectinib in adult and pediatric patients with TRK fusion TC [98]. A total of 28 TC patients (19 PTC, 7 ATC, and 2 FTC) with TRK fusion (43\% NTRK1 fusion and 57\% NTRK3 fusion) were included. ORR was $75 \%$, including $29 \%$ for patients with ATC, and the duration of response ranged from 1.9 to 41.0 months. Median PFS was not reached and the 12-month PFS rate was $81 \%$. AEs were mostly grade 1-2 and only $7 \%$ of patients had grade $\geq 3$ AEs related to larotrectinib, demonstrating a favorable safety profile. The most common AEs are summarized in Table 2. Interestingly, although no preclinical in vitro thyroid model to assess the capacity of NTRK inhibitors to promote redifferentiation is present, a case report was published showing that larotrectinib may restore RAI uptake, likely by inhibiting signaling pathways activated by EML4-NTRK3 in a manner similar to the action of MAPK pathway inhibitors [99].

Entrectinib is another selective inhibitor of TRKA, TRKB, and TRKC, but it is also able to inhibit ALK and ROS1 TK (Table 1). A recently integrated analysis of three phase 1-2 trials of entrectinib in patients with advanced or metastatic NTRK fusion positive solid tumors [100] showed that $7 \%$ of patients had a CR and $50 \%$ a PR with a manageable safety profile. Since the peculiarity of this drug is its capability to penetrate the blood-brain barrier, targeting brain metastasis or primary brain tumors, an updated integrated analysis of the above-mentioned entrectinib studies, focusing on intracranial activity of entrectinib, was presented at 2020 ESMO meeting [101]. According to these authors, the ORR was 50\% and the intracranial efficacy was evident regardless of prior brain radiotherapy. The most common AEs of entrectinib, most of grade 1 or 2, are reported in Table 2. 


\subsection{Systemic Treatment in DTC, PDTC, ATC, and MTC: Specific Inhibitors of RET Oncogene Alterations}

Selpercatinib, known also as LOXO-292, is a highly selective ATP-competitive small molecule RET inhibitor (Table 1), with a half-life of $32 \mathrm{~h}$. As demonstrated in experimental models, this new compound has a very high potency to inhibit different RET alterations, both point mutations and fusions, including the V804M mutation responsible for other TKI resistance [102] and shows an antitumor activity in brain. At variance, its activity against the other receptors, such as VEGFRs, is very low, making the drug highly specific for RET alterations. From May 2017, a phase 1/2 single-arm, multicenter, open-label, multi-cohort clinical trial (LIBRETTO-001 trial, NCT03157128) has been conducted in 65 centers in 12 countries to evaluate the efficacy of LOXO-292 in solid tumors with RET alterations (RET mutations and RET fusions) among with MTC and TC derived from follicular cells (PTC, PDTC, and ATC) [103]. The primary end point was the evaluation of the objective response; whole secondary ones included the duration of response, the PFS, and the safety. The drug was administered orally in 28 day-cycles and the study was conducted in 2 parts, phase 1 (dose escalation) and phase 2 (dose expansion): patients enrolled in the phase 1 dose-escalation group received drug doses ranging from $20 \mathrm{mg}$ once daily to $240 \mathrm{mg}$ twice daily, while patients enrolled in the phase 2 dose escalation group received $160 \mathrm{mg}$ twice daily. The data cut-off date was December 16, 2019. A total of 143 MTC patients were treated across different groups: 55 patients with RET mutations, previously treated with vandetanib or cabozantinib or both, and 88 patients with RET mutations not previously treated with other TKI. Selpercatinib showed a marked and durable anti-tumor activity. In fact, the percentage of patients experiencing a response was $69 \%(95 \% \mathrm{CI}, 55$ to 81$)$ in the first cohort and 73\% (95\% CI, 62 to 82 ) in the second one and interestingly, the first cohort was independent by the number of previous multitargeted treatments administered. The 1-year progression-free survival was $82 \%$ (95\% CI, 69 to 90) in the first group and $92 \%$ (95\% CI, 82 to 97 ) in the second one. Responses were observed across all qualifying $R E T$ mutations, including in patients who had tumors harboring the drug resistant RET mutation V804.

Although the majority of patients enrolled had MTC, 19 DTC patients (13 PTC, 2 PDTC, and 1 HTC) and 2 ATC patients were also included [103]. In 19 patients with previously treated RET fusion-positive DTC, the percentage who had an objective response was $79 \%$, and 1-year PFS was $64 \%$. Of two patients with ATC, one had a durable response for 18 months, with the response ongoing at the end of the study.

The most related AEs were of grade 1-2. Most frequent any grade AEs are reported in Table 2 . The $2 \%$ of all patients discontinued selpercatinib for drug-related AEs, the most common of which were an increased alanine aminotransferase level and drug hypersensitivity. The study is still ongoing and a longer follow-up of the patients involved in this trial will be needed to define the ultimate durability of Selpercatinib efficacy across all cohorts. On the basis of these results, on 8 May 2020, the FDA granted accelerated approval to selpercatinib among other (i.e., non-small cells lung cancers [NSCLC]) for adult and pediatric patients $\geq 12$ years of age with advanced or metastatic RET-mutant TC, both MTC and DTC/ATC, who require systemic therapy [104]. The approved dose was $160 \mathrm{mg}$ twice daily for patients with body weight $\geq 50 \mathrm{~kg}$ and $120 \mathrm{mg}$ twice daily for patients with a lower body weight.

An interventional phase 3 trial with selpercatinib has recently started and is recruiting all over the world. This is a multicenter, randomized, open-label study comparing selpercatinib to physicians' choice of cabozantinib or vandetanib in patients with progressive, advanced, kinase inhibitor naïve, RET-mutant MTC (LIBRETTO-531 trial, NCT04211337) [105]. Patients will be randomized with a 2:1 ratio to two different arms: arm A only selpercatinib and arm B cabozantinib or vandetanib at physician decision, with the possibility of crossover to selpercatinib at progression. Treatment failure-free survival, including radiographic progressive disease, unacceptable toxicity (predefined by protocol), or death from any cause, is the primary endpoint. Secondary end points are the PFS, overall response 
rate, duration of response, OS, PFS 2 by investigator (from baseline to second disease progression or death from any cause), ORR by RET mutation status, safety profile, and pharmacokinetics.

Currently, a few other phase 1-2 studies are ongoing, aiming to confirm the efficacy and tolerability of selpercatinib in different types of solid tumors with $R E T$-alterations: an expanded access trial (NCT03906331) for patients with TC with RET activation who have been previously treated with vandetanib or cabozantinib or other TKI and cannot enter in the phase 3 trial and a phase 2 trial dedicated exclusively to Chinese patients (NCT04280081).

Pralsetinib, also known as BLU-667, is another highly selective RET inhibitor targeting oncogenic RET alterations (Table 1). Previous in vitro studies demonstrated its almost 10fold higher potency over other MKIs against oncogenic RET variants and resistance mutants while in vivo studies showed that the drug is able to inhibit the growth of NSCLC and TC xenografts driven by various RET mutations and fusions without inhibiting VEGFR2 [106]. In the ARROW clinical study (NCT03037385), a phase 1/2 open-label multicenter trial, the drug was studied in patients with RET-mutated TC and other solid tumors. The study was conducted at 75 sites in 11 countries, and consisted of a phase 1 dose escalation, already completed, with administered dose of 30-600 mg daily, that determined the recommended phase 2 pralsetinib dose as $400 \mathrm{mg}$ orally once daily, and a phase 2 expansion cohort defined by tumor type and/or RET alteration in patients treated with $400 \mathrm{mg}$ once daily. The primary objectives in phase 2 included overall response rate and duration of response and safety. At the ESMO Virtual Congress 2020, some preliminary data were shown [107]. At 13 February 2020, in the 79 patients with RET mutation positive MTC the overall response rate was $65 \%$ (51 of 79), in particular it was $74 \%$ in treatment-naïve patients and $60 \%$ in those previously treated with cabozantinib or vandetanib. The 18-months PFS and duration of response were $71 \%$ and $90 \%$ in patients previously treated with other TKI while in treatment-naive patients they were $85 \%$ and $86 \%$, respectively. Responses occurred regardless of RET genotypes.

Preliminary data showed that pralsetinib was also highly active in patients with TC with RET fusions which showed an ORR of $75 \%$ with a median duration of response of 14.5 months.

Regarding pralsetinib's safety, most treatment-related AEs were grade 1-2. The most common of any grade AEs are summarized in Table 2. Treatment-related AEs accounted for $4 \%$ of treatment discontinuations. On the basis of these results, pralsetinib has been approved by FDA both for the treatment of RET-fusion positive NSCLC and, very recently, for $R E T$ fusion-positive TC and RET mutation-positive MTC. Currently, it is under regulatory review in Europe for RET fusion-positive NSCLC.

\subsection{Systemic Treatment in DTC, PDTC, and ATC: Specific Inhibitors of BRAF ${ }^{V 600 E}$ Mutation}

Vemurafenib is an oncogenic BRAF kinase inhibitor (Table 1) approved for BRAFpositive melanoma with a clinical benefit in three patients with $B R A F^{V 600 E}$ positive PTC in a phase 1 trial.

The results of an open-label, non-randomized, phase 2 multicentric trial confirmed the efficacy and safety of vemurafenib in patients with histologically confirmed recurrent or metastatic RAI-refractory PTC and who are positive for the $B R A F^{\mathrm{V} 600 \mathrm{E}}$ mutation [108]. In particular, $P R$ was recorded in $10 / 26$ patients that had never received a multikinase inhibitor. The most common grade 3 and 4 AEs were squamous cell carcinoma of the skin, lymphopenia, and increased $\gamma$-glutamyltransferase. Serious AEs occurred in $62 \%$ of patients which had never received a prior TKI and in $68 \%$ of patients which previously received a TKI. Efficacy of vemurafenib in ATC was not well established since only seven patients were evaluated in a phase 2 study [109] that involved several multiple nonmelanoma cancers with $B R A F^{V 600 E}$ mutations. Of these seven patients, only one showed a $\mathrm{CR}$ and one a PR. To date, no phase 3 study has been designed for vemurafenib in TC. 
Dabrafenib is a selective inhibitor of $B R A F^{V 600 E}$ kinase (Table 1). FDA approved the use of dabrafenib in combination with trametinib, an inhibitor of MEK1-2 kinase, for the treatment of ATC, melanoma, and NSCLC, harboring BRAF V600E mutation. The approval of these two drugs for the treatment of ATC was based on the results of a phase 2 study published in 2018 [110]. In this trial, 16 patients with $B R A F^{V 600 E}$-mutated ATC were evaluable, after they had received prior radiation treatment and/or surgery, and six had received prior systemic therapy. The confirmed ORR was $69 \%$ with seven ongoing responses at the end of the study. Median duration of response, PFS, and OS were not reached as a result of a lack of events, with 12-month estimates of $90 \%, 79 \%$, and $80 \%$, respectively. The safety population was composed of 100 patients who were enrolled with seven rare tumor histologies. Common AEs were fatigue (38\%), pyrexia $(37 \%)$, and nausea (35\%). In 2018, in ESMO meeting, Keam et al. proposed an updated report of the above-mentioned trial, including 28 patients [111]. According to this author, the median PFS was 60 weeks, and the median OS was 86 weeks. Dabrafenib alone and dabrafenib in combination with trametinib were also evaluated in $B R A F^{V 600 E}$ mutated RAI-refractory PTC who had evidence of disease progression within 13 months prior to randomization [112]. This phase 2 trial included 53 patients, and, in particular, 26 patients received dabrafenib (arm A) and 27 patients received the combination treatment ( $\mathrm{arm} \mathrm{B}$ ). PR was reported in $38 \%$ of patients in arm A and in 33\% of patients of arm B while an ORR, defined as a $20 \%$ to $29 \%$ decrease in the sum of targeted lesions, was $50 \%$ and $54 \%$, respectively.

\section{Drugs under Evaluation}

\subsection{Ongoing Studies on Follicular-Derived TC}

Cabozantinib, as mentioned above, is an oral TKI approved for the treatment of advanced MTC but its efficacy was also tested in phase 1 [113] and phase 2 trials [114] in RAI-refractory patients. In the single-arm, open-label phase 1 study, 15 patients with metastatic or surgically unresectable RAI-refractory DTC were enrolled, receiving $140 \mathrm{mg}$ oral daily dose of cabozantinib. Median PFS and OS were not reached but a PR was reported in $53 \%$ of patients. The study showed that the most common AEs were diarrhea, nausea, fatigue, and decreased appetite. Since an objective response to cabozantinib in phase 1 study was achieved in 5/8 patients with DTC previously treated with a VEGFRtargeted therapy, in phase 2 trial the attention was focused on cabozantinib as second or third line of treatment. In particular, only patients with a documented progression of the disease on previous TKI treatment were enrolled $(n=25)$. Twenty-one patients had received only one prior VEGFR-targeted therapy (sorafenib, pazopanib, or cediranib), and four patients had received two of such therapies. Of the 25 patients, $40 \%$ had a PR, 52\% SD, and $8 \%$ had non-evaluable disease. The median PFS and OS were 12.7 months and 34.7 months, respectively, demonstrating that cabozantinib had a clinically significant, durable objective response activity in patients with RAI-refractory DTC who experienced disease progression while taking prior VEGFR-targeted therapy.

A phase 3, multicenter, randomized, double-blind, placebo-controlled study of cabozantinib in subjects with RAI-refractory DTC after prior VEGFR-TKI therapy is currently ongoing (COSMIC-311 trial; NCT03690388). The study provides for the enrollment of 300 patients. Estimated study completion date is December 2022.

Apatinib, an oral inhibitor of VEGFR2, showed clinical activity in preliminary studies involving patients with RAI-refractory DTC. These first results led to a randomized, doubleblind, multicenter phase 3 trial that aimed to evaluate the efficacy and safety of apatinib in 92 patients with RAI-refractory DTC (NCT03048877). The results of the study were recently presented at ESMO meeting 2020 by Lin et al. [115] and they confirmed the efficacy and safety of this drug. Forty-six patients were randomized to apatinib arm and 46 to placebo arm. The median PFS was 22.21 months in apatinib group, and 4.47 months in the placebo group $(p<0.0001)$. ORR was $55.56 \%$ and $2.27 \%$, respectively, while median OS was 29.9 months in the placebo arm, and not reached in apatinib arm $(p=0.0356)$. The 
most frequent treatment-emergent $\geq$ grade 3 AEs in two arms were hypertension $(34.8 \%$ vs. $0 \%$ ), hand-foot syndrome ( $17.4 \%$ vs. $0 \%$ ), and proteinuria ( $17.4 \%$ vs. $2.2 \%)$.

In the last few years, the attention was focused on another TKR inhibitor, anlotinib (AL3818), a novel oral drug targeting VEGFR2 and 3, FGF 1-4, PDGFR $\alpha$ and $\beta$, c-Kit, and $R E T$. Its antitumor effects were demonstrated in various types of carcinoma in a phase 1 clinical trial [116], and, recently, by Ruan et al. [117], both in vitro and in vivo, in advanced TC. Efficacy and safety of anlotinib were also confirmed by a randomized, double-blind, placebo-controlled, multicenter phase 2 trial (NCT02586337) in patients with measurable, pathologically confirmed, locally advanced or metastatic RAI-refractory DTC. The results of this study were recently presented at ESMO meeting 2020 [118]. A total of 113 patients (76 in anlotinib arm and 37 in placebo arm) were enrolled, receiving anlotinib or placebo with a dose of $12 \mathrm{mg}$ QD for 2 weeks followed by a week of rest (2/1 schedule). The median PFS was 40.54 months in anlotinib arm and 8.38 months in placebo arm $(p<0.0001)$. The ORR was $59.21 \%$ in anlotinib arm and no response was observed in placebo arm $(p<0.0001)$. In addition, significant disease control rate benefit was observed for anlotinib treatment (anlotinib arm vs. placebo arm $=97.37 \%$ vs. $78.38 \%, p=0.002$ ). The incidence of treatment-related AEs of two groups was $100 \%$ and $86.49 \%(p=0.003)$. Serious treatmentrelated AEs occurred in $15.79 \%$ of patients receiving anlotinib. The most common AEs in anlotinib arm were hypertension $(84.21 \%)$ and hypertriglyceridemia $(68.42 \%)$.

\subsection{Redifferentiation Treatment in DTC}

In the past, several drugs have been evaluated to redifferentiate metastatic TC through restoration of the NIS activity (i.e., retinoids [119], lithium [120]), but a very modest clinical benefit was found. To date, for redifferentiation in DTC, only MEK and BRAF inhibitors showed some positive results.

Selumetinib is a MEK1/2 inhibitor and it was demonstrated to enhance RAI uptake in DTC [121]. In the study of Ho et al. [121], 20 patients with RAI-refractory DTC received $75 \mathrm{mg} /$ daily of selumetinib and, although 12 of them showed an increased uptake of RAI, only eight reached an adequate threshold for the treatment. According to this study, $8 / 8$ of RAI-treated patients obtained an objective response. $R A S$ positive cases were apparently more responsive. Based on these results, a phase 2 trial with a similar design was started in the USA (NCT02393690). It is still active but with no more recruiting and with no preliminary available results.

A phase 3 study (NCT01843062) evaluating the CR rate for selumetinib in the setting of adjuvant treatment with RAI has been recently reported [122]. The results demonstrated that selumetinib combined with RAI did not improve CR rate in patients with high risk of primary treatment failure. So far, the possibility of using selumetinib in clinical practice is still under evaluation.

As mentioned above, vemurafenib is an oncogenic BRAF kinase inhibitor and it was tested in a pilot study aimed at evaluating the proportion of patients in whom vemurafenib increased RAI incorporation [123]. Twelve BRAF mutated cases were enrolled but only four patients were ${ }^{124}$ iodine responders on vemurafenib and treated with RAI. A tumor regression was observed 6 months after the treatment. Analysis of research of tumor biopsies demonstrated that vemurafenib inhibition of the MAPK pathway was associated with increased thyroid gene expression and RAI uptake.

Dabrafenib is another selective BRAF inhibitor tested to determine whether it can stimulate RAI uptake in $B R A F^{V 600 E}$ mutated unresectable or metastatic RAI-refractory PTC [124]. Ten patients were enrolled and each patient received $150 \mathrm{mg}$ of dabrafenib twice daily for 25 days before TSH stimulated ${ }^{131}$ I whole body scan. Patients whose scan showed new sites of RAI uptake remained on dabrafenib for a longer time, and then were treated with $150 \mathrm{mCi}(5.5 \mathrm{GBq})$ of RAI. Sixty percent of patients demonstrated sites of RAI uptake and all showed a clinical benefit, either PR or SD, on standard radiographic restaging at 3 months. Serum thyroglobulin decreased in $4 / 6$ treated patients. 
Although other studies confirmed that targeted therapy may downregulate MAPK signaling and sensitize tumors to RAI [125], so far they did not reach the clinical practice. Additional studies with a greater number of enrolled patients are required to define AEs, response duration, and survival impact of these drugs.

\subsection{Ongoing Studies on MTC}

Ponatinib (AP24534) is an oral multitargeted TKI that potently inhibits several targets, among which are both the native and mutant forms of BCR-ABL chimeric protein. Quite recently, it has been demonstrated that the drug is also a potent inhibitor of RET kinases and has promising preclinical activity in models of RET-driven MTC [126,127]. A phase 2 open label study was designed to study the efficacy and safety of this compound in advanced or metastatic MTC (NCT03838692). The primary end point of this study is to determine the objective overall response rate to ponatinib, both in patients previously treated with cabozantinib or vandetanib and with or without RET mutated tumors. The drug was administered at a daily dose of $45 \mathrm{mg}$. The estimated study completion is June 2021.

Anlotinib (AL3818) is a novel multi-targeted TKI, inhibiting tumor angiogenesis and proliferative signaling. After the results of a phase 2 single-arm trial (NCT01874873) demonstrating that anlotinib has a durable antitumor activity with a manageable adverse event profile in locally advanced or metastatic MTC, a subsequent randomized, doubleblind, placebo-controlled, multicenter clinical trial was conducted in China to compare the efficacy and safety of anlotinib versus placebo in MTC patients (ALTER01031 trial, NCT02586350). The primary endpoint was the PFS. Previous TKI therapies were not allowed. At the 2019 ASCO congress, some results were presented [71]: 91 patients were randomized: 62 to anlotinib arm and 29 to placebo arm and median PFS was 20.67 months (95\% CI, 14.03-34.63) in anlotinib arm vs. 11.07 months (95\% CI, 5.82-14.32) in placebo arm (HR 0.53, $p=0.0289$ ). The most common AEs in anlotinib arm were hand-foot syndrome, hypertension, hypertriglyceridemia, and diarrhea.

TPX-0046 is a 3rd generation, highly selective TKI tested, so far, in drug-resistant and naïve RET-driven cancer models [128]. This drug is very promising, especially for cases in which a resistance to the other TKIs has been developed through the induction of RET-810 mutation. Hopefully, in vivo clinical trials will confirm these in vitro studies.

\subsection{Immunotherapy: The Present and the Future}

To date, no immunotherapy has been approved for advanced TC, but several preclinical and clinical trials together with case reports have been reported. A few studies are ongoing, using immune checkpoint inhibitors alone or in combined strategy.

In the phase Ib KEYNOTE trial, the use of pembrolizumab (anti PD-1) in monotherapy was studied in TC including PTC and FTC showing an ORR of 9\% and reduction of tumor size of $35-50 \%$ [129]. The use of another anti PD-1 agent in monotherapy (spartalizumab) was evaluated in progressive ATC and an ORR of 19\% was observed together with a partial and complete radiological response in five and three patients, respectively [130]. In a randomized phase 2 clinical trial (NCT03246958), still ongoing but no longer recruiting, the efficacy of the combination of nivolumab (anti PD-1) and ipilimumab (anti CTLA-4) was evaluated in RAI refractory DTC, ATC, and MTC.

Considering the slow onset of immunotherapy efficacy and the evidence that immune checkpoint inhibition alone is not curative in most patients, several combined approaches with chemo and target therapy are under investigation. For example, the association of encorafenib (BRAF inhibitor), binimetinib (MEK inhibitor), and nivolumab is under evaluation in $B R A F^{V 600 E}$ mutated TC in a randomized open label clinical trial still recruiting (NCT04061980). Combined approaches with radio and chemotherapy were also evaluated in ATC: the association of pembrolizumab and chemoradiation [131] (doxorubicin or docetaxel+ Volumetric Modulated Arc Therapy) showed favorable but also limited results due to toxicity as well as the combination of durvalumab (anti PD-L1), tremelimubab (anti CTLA-4), and radio or chemotherapy [132]. 
Based on the evidence that VEGF inhibition can reverse the immune suppression in the tumoral microenvironment, multiple clinical trials with VEGF and/or VEGF inhibitor and immune checkpoint inhibitors have been designed. In an ongoing phase 2 clinical trial, the use of pemproblizumab+lenvatinib was investigated in unresectable ATC (NCT04171622) and also in a randomized study in a small group of advanced ATC and PDTC [133] with an ORR of $75 \%$. Moreover, the same combination is under study in DTC and PDTC (NCT02973997) in naïve or progressing after lenvatinib patients. A triple combined therapy is under evaluation for DTC and PDTC using cabozantinib plus nivolumab and ipilimumab (NCT03914300). A comparison of different combined approaches based on mutational status of ATC and PDTC cancer is ongoing at the MD Anderson Cancer Center: all patients received atezolizumab plus other treatments according to the stratification in four groups of therapy based on the presence of $B R A F$ mutation (vemurafenib plus cobimetinib), $R A S$, or NIF1/2 (only combimetinib) or the absence (bevacizumab plus paclitaxel) (NCT03181100).

Few studies are ongoing for MTC. A phase 2 trial of pembrolizumab is ongoing in recurrent or metastatic MTC (NCT03072160) as well as the use of a cancer vaccine GI-6207 targeting the CEA in a randomized phase 2 clinical trial (NCT01856920). A future prospect for MTC patients might be the combination of specific RET inhibitors (LOXO292 and BLU-667) with immune checkpoint inhibitors.

So far, immunotherapy is not yet applicable in clinical practice for patients with advanced TC but, as demonstrated by the numerous active trials, there is great interest and hope.

\section{Open Issues}

Despite good results, both from clinical trials and clinical practice, some problems are still present in the use of these therapies. For example, problems are the balance between drug efficacy and management of AEs, the drug resistance, and the absence of recognized predictors of response. While for AEs, thanks to the daily use of these drugs in clinical practice, some preventive strategies have been implemented to avoid toxicity and to prolong the use and efficacy of the treatment [134], the questions regarding the escape phenomenon and the finding of predictive markers of response are still open.

The availability of predictive markers would help to select patients with higher probability to benefit from the treatment, but the research into these genetic and/or biological markers is still ongoing. The pre-treatment analysis of the mutational pattern of tumor samples might have a role in the selection of patients, but, in almost all clinical trials, the drug response was demonstrated to not be strictly related to the mutational status of tumors with some exceptions. For examples, for cabozantinib the presence of M918T somatic RET mutation in tumor sample seems to be associated with better overall survival [94], while on the contrary for vandetanib a drug resistance was associated with V804M RET mutation [102]. Furthermore, the occurrence of same AEs has been proposed as a predictive response marker of drug efficacy. For example, hypertension was significantly correlated with improved outcomes during lenvatinib treatment [135], while the occurrence of any type of AEs was associated with long-term durable response for vandetanib [91]. The same was observed for skin toxicity during sorafenib treatment in hepatocellular carcinoma [136], for hypertension, hypothyroidism, and diarrhea for cabozantinib in renal cancer [137], and proteinuria in MTC [138]. In addition, the expression profiling of miRNAs in tumor tissue and/or circulating cytokine/angiogenic factors in blood samples are under study. For example, baseline higher levels of fibroblast growth factor 23 and angiopoietin-2 were demonstrated to be predictive of a better progression-free survival in DTC treated with lenvatinib [139]. The same was demonstrated for higher expression levels in tumor samples of FLT1, FLT3, and VEGFB for vandetanib treatment in sporadic MTC [140].

Drug resistance is one of the most critical and unavoidable problems for the clinician. Many mechanisms limit drug efficacy but especially the tumor heterogenicity, which is related not only to a genetic intratumor heterogenicity but also to epigenetic alterations induced by the molecules secreted by the tumor microenvironment. Much evidence shows 
that a genetic heterogenicity is present in TC and related to different subclones within the same tumor [141]. This heterogenicity can evolve during tumor progression or as a consequence of a drug-dependent selection of a pre-existing or newly acquired resistant clone [142]. Other than this mechanism, the crosstalk between tumor microenvironment cells ( $\mathrm{T}$ cell, fibroblast, macrophages) and cancer cells can also alter tumor phenotype by increasing tumor plasticity and its stem potential [143]. The use of "liquid biopsies" and search of circulating DNA seems to be an important emergent strategy to monitor both the treatment efficacy and the development of new mutations able to induce drug resistance [144].

\section{Conclusions}

Thyroid cancer has different histologies and molecular identities. The initial treatment is always represented by total thyroidectomy plus/minus lymphadenectomy followed by, whenever appropriate, RAI treatment. This initial treatment can cure the vast majority of TC but the subgroups of multimetastatic, poorly differentiated, and anaplastic require other therapies varying from local treatments to systemic therapies. Local treatments are always preferred when the disease is oligometastatic or, if multimetastatic, with only one specific lesion that is growing. When the disease is advanced, multimetastatic, and progressive, the systemic therapy should be initiated and nowadays there are already four different types of TKIs approved; two for MTC and two for RAI refractory DTC and PDTC. The TKIs therapy changed the outcome of advanced metastatic TC patients but, although a prolonged PFS was well documented, an improvement of the OS has yet to be established. Clinicians should bear in mind that TKIs are not curative and a continuative treatment is needed to maintain a response to the disease. For this reason, it is very important that other studies will be performed and other therapeutic strategies will be explored. Moreover, the first generation of TKIs, being multikinase inhibitors, has a lot of side effects that may reduce the quality of life of these patients, frequently leading to a discontinuation of the drug with an important impact on neoplastic disease recurrence. For this reason, new therapeutic approaches are needed and, according to preliminary studies, a new second generation of selective TKIs seems to be a good option able to balance efficacy and AEs in patients with advanced, metastatic, and progressive TC.

Funding: This work has been supported by Associazione Italiana Ricerca sul Cancro (AIRC, Investigator grant 2018, project code 21790) and Ministero dell'Istruzione, dell'Università e della Ricerca (PRIN 2017, protocol 2017YTWKWH).

Conflicts of Interest: R.E. is a consultant for Bayer, EISAI, Loxo, Ipsen, Lilly, Astra Zeneca, Exelixis, Genzyme, but this activity did not influence this work, which has been written independently.

\section{References}

1. Institute, N.C. Surveillance Epidemiology and End Results Program: SEER Stat Facts: Thyroid Cancer. Available online: https:/ / seer.cancer.gov/statfacts/html/thyro.html (accessed on 16 March 2021).

2. Pellegriti, G.; Frasca, F.; Regalbuto, C.; Squatrito, S.; Vigneri, R. Worldwide increasing incidence of thyroid cancer: Update on epidemiology and risk factors. J. Cancer Epidemiol. 2013, 2013. [CrossRef] [PubMed]

3. Dunlap, Q.; Davies, L. Differentiated Thyroid Cancer Incidence. In Surgery of the Thyroid and Parathyroid Glands; Elsevier: Amsterdam, The Netherlands, 2021; pp. 174-180.e2.

4. $\quad$ Eustatia-Rutten, C.F.A.; Corssmit, E.P.M.; Biermasz, N.R.; Pereira, A.M.; Romijn, J.A.; Smit, J.W. Survival and death causes in differentiated thyroid carcinoma. J. Clin. Endocrinol. Metab. 2006, 91, 313-319. [CrossRef]

5. Durante, C.; Haddy, N.; Baudin, E.; Leboulleux, S.; Hartl, D.; Travagli, J.P.; Caillou, B.; Ricard, M.; Lumbroso, J.D.; De Vathaire, F.; et al. Long-term outcome of 444 patients with distant metastases from papillary and follicular thyroid carcinoma: Benefits and limits of radioiodine therapy. J. Clin. Endocrinol. Metab. 2006, 91, 2892-2899. [CrossRef] [PubMed]

6. Nam, S.H.; Bae, M.R.; Roh, J.L.; Gong, G.; Cho, K.J.; Choi, S.H.; Nam, S.Y.; Kim, S.Y. A comparison of the 7th and 8th editions of the AJCC staging system in terms of predicting recurrence and survival in patients with papillary thyroid carcinoma. Oral Oncol. 2018, 87, 158-164. [CrossRef] [PubMed]

7. Hiltzik, D.; Carlson, D.L.; Tuttle, R.M.; Chuai, S.; Ishill, N.; Shaha, A.; Shah, J.P.; Singh, B.; Ghossein, R.A. Poorly differentiated thyroid carcinomas defined on the basis of mitosis and necrosis: A clinicopathologic study of 58 patients. Cancer 2006, 106, 1286-1295. [CrossRef] 
8. Volante, M.; Collini, P.; Nikiforov, Y.E.; Sakamoto, A.; Kakudo, K.; Katoh, R.; Lloyd, R.V.; LiVolsi, V.A.; Papotti, M.; SobrinhoSimoes, M.; et al. Poorly differentiated thyroid carcinoma: The Turin proposal for the use of uniform diagnostic criteria and an algorithmic diagnostic approach. Am. J. Surg. Pathol. 2007, 31, 1256-1264. [CrossRef] [PubMed]

9. Ibrahimpasic, T.; Ghossein, R.; Carlson, D.L.; Chernichenko, N.; Nixon, I.; Palmer, F.L.; Lee, N.Y.; Shaha, A.R.; Patel, S.G.; Tuttle, R.M.; et al. Poorly differentiated thyroid carcinoma presenting with gross extrathyroidal extension: 1986-2009 memorial Sloan-Kettering cancer center experience. Thyroid 2013, 23, 997-1002. [CrossRef]

10. Ho, A.S.; Luu, M.; Barrios, L.; Balzer, B.L.; Bose, S.; Fan, X.; Walgama, E.; Mallen-St. Clair, J.; Alam, U.; Shafqat, I.; et al. Prognostic Impact of Histologic Grade for Papillary Thyroid Carcinoma. Ann. Surg. Oncol. 2020, 28, 1731-1739. [CrossRef]

11. Haugen, B.R. 2015 American Thyroid Association Management Guidelines for Adult Patients with Thyroid Nodules and Differentiated Thyroid Cancer: What is new and what has changed? Cancer 2017, 123, 372-381. [CrossRef]

12. Schlumberger, M.; Challeton, C.; De Vathaire, F.; Travagli, J.P.; Gardet, P.; Lumbroso, J.D.; Francese, C.; Fontaine, F.; Ricard, M.; Parmentier, C. Radioactive Iodine Treatment and External Radiotherapy for Lung and Bone Metastases from Thyroid Carcinoma. J. Nucl. Med. 1996, 37, 598-605.

13. Bernier, M.O.; Leenhardt, L.; Hoang, C.; Aurengo, A.; Mary, J.Y.; Menegaux, F.; Enkaoua, E.; Turpin, G.; Chiras, J.; Saillant, G.; et al. Survival and therapeutic modalities in patients with bone metastases of differentiated thyroid carcinomas. J. Clin. Endocrinol. Metab. 2001, 86, 1568-1573. [CrossRef]

14. Dupuy, D.E.; Monchik, J.M.; Decrea, C.; Pisharodi, L. Radiofrequency ablation of regional recurrence from well-differentiated thyroid malignancy. Surgery 2001, 130, 971-977. [CrossRef] [PubMed]

15. Lee, S.J.; Jung, S.L.; Kim, B.S.; Ahn, K.J.; Choi, H.S.; Lim, D.J.; Kim, M.H.; Bae, J.S.; Kim, M.S.; Jung, C.K.; et al. Radiofrequency ablation to treat loco-regional recurrence of well-differentiated thyroid carcinoma. Korean J. Radiol. 2014, 15, 817-826. [CrossRef]

16. Lewis, B.D.; Hay, I.D.; Charboneau, J.W.; McIver, B.; Reading, C.C.; Goellner, J.R. Percutaneous ethanol injection for treatment of cervical lymph node metastases in patients with papillary thyroid carcinoma. Am. J. Roentgenol. 2002, 178, 699-704. [CrossRef]

17. Kim, S.Y.; Kim, S.M.; Chang, H.; Kim, B.W.; Lim, C.Y.; Lee, Y.S.; Chang, H.S.; Park, C.S. Long-term outcomes of ethanol injection therapy for locally recurrent papillary thyroid cancer. Eur. Arch. Oto-Rhino-Laryngol. 2017, 274, 3497-3501. [CrossRef] [PubMed]

18. Eustatia-Rutten, C.F.A.; Romijn, J.A.; Guijt, M.J.; Vielvoye, G.J.; Van Den Berg, R.; Corssmit, E.P.M.; Pereira, A.M.; Smit, J.W.A Outcome of palliative embolization of bone metastases in differentiated thyroid carcinoma. J. Clin. Endocrinol. Metab. 2003, 88, 3184-3189. [CrossRef]

19. Molinaro, E.; Romei, C.; Biagini, A.; Sabini, E.; Agate, L.; Mazzeo, S.; Materazzi, G.; Sellari-Franceschini, S.; Ribechini, A.; Torregrossa, L.; et al. Anaplastic thyroid carcinoma: From clinicopathology to genetics and advanced therapies. Nat. Rev. Endocrinol. 2017, 13, 644-660. [CrossRef] [PubMed]

20. Chiacchio, S.; Lorenzoni, A.; Boni, G.; Rubello, D.; Elisei, R.; Mariani, G. Anaplastic thyroid cancer: Prevalence, diagnosis and treatment. Minerva Endocrinol. 2008, 33, 341-357. [PubMed]

21. Prasongsook, N.; Kumar, A.; Chintakuntlawar, A.V.; Foote, R.L.; Kasperbauer, J.; Molina, J.; Garces, Y.; Ma, D.; Neben Wittich, M.A.; Rubin, J.; et al. Survival in response to multimodal therapy in anaplastic thyroid cancer. J. Clin. Endocrinol. Metab. 2017, 102, 4506-4514. [CrossRef]

22. Smallridge, R.C.; Ain, K.B.; Asa, S.L.; Bible, K.C.; Brierley, J.D.; Burman, K.D.; Kebebew, E.; Lee, N.Y.; Nikiforov, Y.E.; Rosenthal, M.S.; et al. American thyroid association guidelines for management of patients with anaplastic thyroid cancer. Thyroid 2012, 22, 1104-1139. [CrossRef]

23. GHARIB, H.; McCONAHEY, W.M.; TIEGS, R.D.; BERGSTRALH, E.J.; GOELLNER, J.R.; GRANT, C.S.; van HEERDEN, J.A.; SIZEMORE, G.W.; HAY, I.D. Medullary Thyroid Carcinoma: Clinicopathologic Features and Long-Term Follow-Up of 65 Patients Treated During 1946 Through 1970. Mayo Clin. Proc. 1992, 67, 934-940. [CrossRef]

24. Schlumberger, M.; Bastholt, L.; Dralle, H.; Jarzab, B.; Pacini, F.; Smit, J.W.A. 2012 European Thyroid Association Guidelines for Metastatic Medullary Thyroid Cancer. Eur. Thyroid J. 2012, 1, 5-14. [CrossRef]

25. Wells, S.A.; Asa, S.L.; Dralle, H.; Elisei, R.; Evans, D.B.; Gagel, R.F.; Lee, N.; MacHens, A.; Moley, J.F.; Pacini, F.; et al. Revised American thyroid association guidelines for the management of medullary thyroid carcinoma. Thyroid 2015, 25, 567-610 [CrossRef]

26. Ringe, K.I.; Panzica, M.; Von Falck, C. Thermoablation of Bone Tumors. In RoFo Fortschritte auf dem Gebiet der Rontgenstrahlen und der Bildgebenden Verfahren; Georg Thieme Verlag KG: Stuttgart, Germany, 2016.

27. Eisele, R.M. Advances in local ablation of malignant liver lesions. World J. Gastroenterol. 2016, 22, 3885-3891. [CrossRef]

28. Roche, A.; Girish, B.V.; de Baère, T.; Baudin, E.; Boige, V.; Elias, D.; Lasser, P.; Schlumberger, M.; Ducreux, M. Trans-catheter arterial chemoembolization as first-line treatment for hepatic metastases from endocrine tumors. Eur. Radiol. 2003, 13, 136-140. [CrossRef]

29. Lupoli, G.A.; Fonderico, F.; Fittipaldi, M.R.; Colarusso, S.; Panico, A.; Cavallo, A.; Di Micco, L.; Lupoli, G. The role of somatostatin analogs in the management of medullary thyroid carcinoma. J. Endocrinol. Investig. 2003, 26, 72-74.

30. Salavati, A.; Puranik, A.; Kulkarni, H.R.; Budiawan, H.; Baum, R.P. Peptide Receptor Radionuclide Therapy (PRRT) of Medullary and Nonmedullary Thyroid Cancer Using Radiolabeled Somatostatin Analogues. Semin. Nucl. Med. 2016, 46, 215-224. [CrossRef]

31. Elisei, R.; Ugolini, C.; Viola, D.; Lupi, C.; Biagini, A.; Giannini, R.; Romei, C.; Miccoli, P.; Pinchera, A.; Basolo, F. BRAFV600E mutation and outcome of patients with papillary thyroid carcinoma: A 15-year median follow-up study. J. Clin. Endocrinol. Metab. 2008, 93, 3943-3949. [CrossRef] [PubMed] 
32. Prete, A.; Borges de Souza, P.; Censi, S.; Muzza, M.; Nucci, N.; Sponziello, M. Update on Fundamental Mechanisms of Thyroid Cancer. Front. Endocrinol. 2020, 11. [CrossRef] [PubMed]

33. Agrawal, N.; Akbani, R.; Aksoy, B.A.; Ally, A.; Arachchi, H.; Asa, S.L.; Auman, J.T.; Balasundaram, M.; Balu, S.; Baylin, S.B.; et al. Integrated Genomic Characterization of Papillary Thyroid Carcinoma. Cell 2014, 159, 676-690. [CrossRef] [PubMed]

34. Zarkesh, M.; Zadeh-Vakili, A.; Azizi, F.; Foroughi, F.; Akhavan, M.M.; Hedayati, M. Altered Epigenetic Mechanisms in Thyroid Cancer Subtypes. Mol. Diagn. Ther. 2018, 22, 41-56. [CrossRef] [PubMed]

35. Ganly, I.; Makarov, V.; Deraje, S.; Dong, Y.Y.; Reznik, E.; Seshan, V.; Nanjangud, G.; Eng, S.; Bose, P.; Kuo, F.; et al. Integrated Genomic Analysis of Hürthle Cell Cancer Reveals Oncogenic Drivers, Recurrent Mitochondrial Mutations, and Unique Chromosomal Landscapes. Cancer Cell 2018, 34, 256-270.e5. [CrossRef]

36. Kebebew, E.; Weng, J.; Bauer, J.; Ranvier, G.; Clark, O.H.; Duh, Q.Y.; Shibru, D.; Bastian, B.; Griffin, A. The prevalence and prognostic value of BRAF mutation in thyroid cancer. Ann. Surg. 2007, 246, 466-470. [CrossRef]

37. Ciampi, R.; Romei, C.; Pieruzzi, L.; Tacito, A.; Molinaro, E.; Agate, L.; Bottici, V.; Casella, F.; Ugolini, C.; Materazzi, G.; et al. Classical point mutations of RET, BRAF and RAS oncogenes are not shared in papillary and medullary thyroid cancer occurring simultaneously in the same gland. J. Endocrinol. Investig. 2017, 40, 55-62. [CrossRef] [PubMed]

38. Chakravarty, D.; Santos, E.; Ryder, M.; Knauf, J.A.; Liao, X.H.; West, B.L.; Bollag, G.; Kolesnick, R.; Thin, T.H.; Rosen, N.; et al. Small-molecule MAPK inhibitors restore radioiodine incorporation in mouse thyroid cancers with conditional BRAF activation. J. Clin. Investig. 2011, 121, 4700-4711. [CrossRef]

39. Censi, S.; Cavedon, E.; Bertazza, L.; Galuppini, F.; Watutantrige-Fernando, S.; De Lazzari, P.; Nacamulli, D.; Pennelli, G.; Fassina, A.; Iacobone, M.; et al. Frequency and significance of Ras, Tert promoter, and Braf mutations in cytologically indeterminate thyroid nodules: A monocentric case series at a tertiary-level Endocrinology unit. Front. Endocrinol. 2017, 8. [CrossRef] [PubMed]

40. Ciampi, R.; Mian, C.; Fugazzola, L.; Cosci, B.; Romei, C.; Barollo, S.; Cirello, V.; Bottici, V.; Marconcini, G.; Rosa, P.M.; et al. Evidence of a low prevalence of ras mutations in a large medullary thyroid cancer series. Thyroid 2013, 23, 50-57. [CrossRef]

41. Ciampi, R.; Romei, C.; Ramone, T.; Prete, A.; Tacito, A.; Cappagli, V.; Bottici, V.; Viola, D.; Torregrossa, L.; Ugolini, C.; et al. Genetic Landscape of Somatic Mutations in a Large Cohort of Sporadic Medullary Thyroid Carcinomas Studied by Next-Generation Targeted Sequencing. iScience 2019, 20, 324-336. [CrossRef]

42. Tirrò, E.; Martorana, F.; Romano, C.; Vitale, S.R.; Motta, G.; Di Gregorio, S.; Massimino, M.; Pennisi, M.S.; Stella, S.; Puma, A.; et al. Molecular alterations in thyroid cancer: From bench to clinical practice. Genes 2019, 10, 709. [CrossRef] [PubMed]

43. Xing, M. Molecular pathogenesis and mechanisms of thyroid cancer. Nat. Rev. Cancer 2013, 13, 184-199. [CrossRef]

44. Liu, Z.; Hou, P.; Ji, M.; Guan, H.; Studeman, K.; Jensen, K.; Vasko, V.; El-Naggar, A.K.; Xing, M.M. Highly prevalent genetic alterations in receptor tyrosine kinases and phosphatidylinositol 3-kinase/Akt and mitogen-activated protein kinase pathways in anaplastic and follicular thyroid cancers. J. Clin. Endocrinol. Metab. 2008, 93, 3106-3116. [CrossRef]

45. Ricarte-Filho, J.C.; Ryder, M.; Chitale, D.A.; Rivera, M.; Heguy, A.; Ladanyi, M.; Janakiraman, M.; Solit, D.; Knauf, J.A.; Tuttle, R.M.; et al. Mutational profile of advanced primary and metastatic radioactive iodine-refractory thyroid cancers reveals distinct pathogenetic roles for BRAF, PIK3CA, and AKT1. Cancer Res. 2009, 69, 4885-4893. [CrossRef]

46. Paes, J.E.; Ringel, M.D. Dysregulation of the Phosphatidylinositol 3-Kinase Pathway in Thyroid Neoplasia. Endocrinol. Metab. Clin. N. Am. 2008, 37, 375-387. [CrossRef] [PubMed]

47. Du, Z.; Lovly, C.M. Mechanisms of receptor tyrosine kinase activation in cancer. Mol. Cancer 2018, 17. [CrossRef]

48. Santoro, M.; Moccia, M.; Federico, G.; Carlomagno, F. Ret gene fusions in malignancies of the thyroid and other tissues. Genes 2020, 11, 424. [CrossRef] [PubMed]

49. Suzuki, K.; Saenko, V.; Yamashita, S.; Mitsutake, N. Radiation-induced thyroid cancers: Overview of molecular signatures. Cancers 2019, 11, 1290. [CrossRef]

50. Taccaliti, A.; Silvetti, F.; Palmonella, G.; Boscaro, M. Genetic Alterations in Medullary Thyroid Cancer: Diagnostic and Prognostic Markers. Curr. Genom. 2011, 12, 618-625. [CrossRef] [PubMed]

51. Krampitz, G.W.; Norton, J.A. RET gene mutations (genotype and phenotype) of multiple endocrine neoplasia type 2 and familial medullary thyroid carcinoma. Cancer 2014, 120, 1920-1931. [CrossRef]

52. Chernock, R.D.; Hagemann, I.S. Molecular pathology of hereditary and sporadic medullary thyroid carcinomas. Am. J. Clin. Pathol. 2015, 143, 768-777. [CrossRef]

53. Greco, A.; Miranda, C.; Pierotti, M.A. Rearrangements of NTRK1 gene in papillary thyroid carcinoma. Mol. Cell. Endocrinol. 2010, 321, 44-49. [CrossRef] [PubMed]

54. Amatu, A.; Sartore-Bianchi, A.; Siena, S. NTRK gene fusions as novel targets of cancer therapy across multiple tumour types. ESMO Open 2016, 1. [CrossRef]

55. Yakushina, V.D.; Lerner, L.V.; Lavrov, A.V. Gene fusions in thyroid cancer. Thyroid 2018, 28, 158-167. [CrossRef]

56. Cocco, E.; Scaltriti, M.; Drilon, A. NTRK fusion-positive cancers and TRK inhibitor therapy. Nat. Rev. Clin. Oncol. 2018, 15, 731-747. [CrossRef] [PubMed]

57. Murugan, A.K.; Xing, M.M. Anaplastic thyroid cancers harbor novel oncogenic mutations of the ALK gene. Cancer Res. 2011, 71, 4403-4411. [CrossRef]

58. Quail, D.F.; Joyce, J.A. Microenvironmental regulation of tumor progression and metastasis. Nat. Med. 2013, 19, 1423-1437. [CrossRef] [PubMed] 
59. Wu, Y.C.; Tang, S.J.; Sun, G.H.; Sun, K.H. CXCR7 mediates TGFß1-promoted EMT and tumor-initiating features in lung cancer. Oncogene 2016, 35, 2123-2132. [CrossRef] [PubMed]

60. Armstrong, M.J.; Yang, H.; Yip, L.; Ohori, N.P.; McCoy, K.L.; Stang, M.T.; Hodak, S.P.; Nikiforova, M.N.; Carty, S.E.; Nikiforov, Y.E. PAX8/PPAR $\gamma$ rearrangement in thyroid nodules predicts follicular-pattern carcinomas, in particular the encapsulated follicular variant of papillary carcinoma. Thyroid 2014, 24, 1369-1374. [CrossRef] [PubMed]

61. Raman, P.; Koenig, R.J. Pax-8-PPAR- $\gamma 3$ fusion protein in thyroid carcinoma. Nat. Rev. Endocrinol. 2014, 10, 616-623. [CrossRef]

62. Manzella, L.; Stella, S.; Pennisi, M.S.; Tirrò, E.; Massimino, M.; Romano, C.; Puma, A.; Tavarelli, M.; Vigneri, P. New insights in thyroid cancer and p53 family proteins. Int. J. Mol. Sci. 2017, 18, 1325. [CrossRef]

63. Sastre-Perona, A.; Santisteban, P. Role of the Wnt pathway in thyroid cancer. Front. Endocrinol. 2012, 3. [CrossRef] [PubMed]

64. Parr, C.; Mirzaei, N.; Christian, M.; Sastre, M. Activation of the Wnt/ $\beta$-catenin pathway represses the transcription of the $\beta$-amyloid precursor protein cleaving enzyme (BACE1) via binding of T-cell factor-4 to BACE1 promoter. FASEB J. 2015, 29, 623-635. [CrossRef]

65. Liu, R.; Xing, M. TERT promoter mutations in thyroid cancer. Endocr. Relat. Cancer 2016, 23, R143-R155. [CrossRef]

66. Gupta, S.; Patel, A.; Folstad, A.; Fenton, C.; Dinauer, C.A.; Tuttle, R.M.; Conran, R.; Francis, G.L. Infiltration of Differentiated Thyroid Carcinoma by Proliferating Lymphocytes Is Associated with Improved Disease-Free Survival for Children and Young Adults1. J. Clin. Endocrinol. Metab. 2001, 86, 1346-1354. [CrossRef] [PubMed]

67. Yin, H.; Tang, Y.; Guo, Y.; Wen, S. Immune microenvironment of thyroid cancer. J. Cancer 2020, 11, 4884-4896. [CrossRef] [PubMed]

68. Yu, H.; Huang, X.; Liu, X.; Jin, H.; Zhang, G.; Zhang, Q.; Yu, J. Regulatory T cells and plasmacytoid dendritic cells contribute to the immune escape of papillary thyroid cancer coexisting with multinodular non-toxic goiter. Endocrine 2013, 44, $172-181$. [CrossRef]

69. French, J.D.; Weber, Z.J.; Fretwell, D.L.; Said, S.; Klopper, J.P.; Haugen, B.R. Tumor-associated lymphocytes and increased FoxP3+ regulatory $\mathrm{T}$ cell frequency correlate with more aggressive papillary thyroid cancer. J. Clin. Endocrinol. Metab. 2010, 95, 2325-2333. [CrossRef]

70. Condeelis, J.; Pollard, J.W. Macrophages: Obligate partners for tumor cell migration, invasion, and metastasis. Cell 2006, 124, 263-266. [CrossRef] [PubMed]

71. Li, D.; Tang, P.Z.; Chen, X.; Ge, M.; Zhang, Y.; Guo, Z.; Wang, J.; Shi, F.; Zhang, J.; Cheng, Y.; et al. Anlotinib treatment in locally advanced or metastatic medullary thyroid carcinoma: A multicenter, randomized, double-blind, placebo-controlled phase IIB trial. J. Clin. Oncol. 2019, 37, 6019. [CrossRef]

72. Qing, W.; Fang, W.Y.; Ye, L.; Shen, L.Y.; Zhang, X.F.; Fei, X.C.; Chen, X.; Wang, W.Q.; Li, X.Y.; Xiao, J.C.; et al. Density of tumor-associated macrophages correlates with lymph node metastasis in papillary thyroid carcinoma. Thyroid 2012, 22, 905-910. [CrossRef]

73. Ahn, S.; Kim, T.H.; Kim, S.W.; Ki, C.S.; Jang, H.W.; Kim, J.S.; Kim, J.H.; Choe, J.H.; Shin, J.H.; Hahn, S.Y.; et al. Comprehensive screening for PD-L1 expression in thyroid cancer. Endocr. Relat. Cancer 2017, 24, 97-106. [CrossRef]

74. Na, K.J.; Choi, H. Immune landscape of papillary thyroid cancer and immunotherapeutic implications. Endocr. Relat. Cancer 2018, 25, 523-531. [CrossRef] [PubMed]

75. French, J.D. Immunotherapy for advanced thyroid cancers - rationale, current advances and future strategies. Nat. Rev. Endocrinol. 2020, 16, 629-641. [CrossRef]

76. Gupta-Abramson, V.; Troxel, A.B.; Nellore, A.; Puttaswamy, K.; Redlinger, M.; Ransone, K.; Mandel, S.J.; Flaherty, K.T.; Loevner, L.A.; O’Dwyer, P.J.; et al. Phase II trial of sorafenib in advanced thyroid cancer. J. Clin. Oncol. 2008, 26, 4714-4719. [CrossRef] [PubMed]

77. Shah, M.H.; Kloos, R.T.; Ringel, M.D.; Knopp, M.V.; Hall, N.C.; King, M.; Stevens, R.; Liang, J.; Wakely, P.E.; Vasko, V.V.; et al. Phase II trial of sorafenib in metastatic thyroid cancer. J. Clin. Oncol. 2009, 27, 1675-1684. [CrossRef]

78. Brose, M.S.; Nutting, C.M.; Jarzab, B.; Elisei, R.; Siena, S.; Bastholt, L.; De La Fouchardiere, C.; Pacini, F.; Paschke, R.; Shong, Y.K.; et al. Sorafenib in radioactive iodine-refractory, locally advanced or metastatic diff erentiated thyroid cancer: A randomised, double-blind, phase 3 trial. Lancet 2014, 384, 319-328. [CrossRef]

79. Sherman, E.J.; Dunn, L.A.; Ho, A.L.; Baxi, S.S.; Ghossein, R.A.; Fury, M.G.; Haque, S.; Sima, C.S.; Cullen, G.; Fagin, J.A.; et al. Phase 2 study evaluating the combination of sorafenib and temsirolimus in the treatment of radioactive iodine-refractory thyroid cancer. Cancer 2017, 123, 4114-4121. [CrossRef] [PubMed]

80. Savvides, P.; Nagaiah, G.; Lavertu, P.; Fu, P.; Wright, J.J.; Chapman, R.; Wasman, J.; Dowlati, A.; Remick, S.C. Phase II trial of sorafenib in patients with advanced anaplastic carcinoma of the thyroid. Thyroid 2013, 23, 600-604. [CrossRef]

81. Mooney, C.J.; Nagaiah, G.; Fu, P.; Wasman, J.K.; Cooney, M.M.; Savvides, P.S.; Bokar, J.A.; Dowlati, A.; Wang, D.; Agarwala, S.S.; et al. A phase II trial of fosbretabulin in advanced anaplastic thyroid carcinoma and correlation of baseline serum-soluble intracellular adhesion molecule-1 with outcome. Thyroid 2009, 19, 233-240. [CrossRef]

82. Cabanillas, M.E.; Schlumberger, M.; Jarzab, B.; Martins, R.G.; Pacini, F.; Robinson, B.; McCaffrey, J.C.; Shah, M.H.; Bodenner, D.L.; Topliss, D.; et al. A phase 2 trial of lenvatinib (E7080) in advanced, progressive, radioiodine-refractory, differentiated t. Cancer 2015, 121, 2749-2756. [CrossRef] 
83. Schlumberger, M.; Tahara, M.; Wirth, L.J.; Robinson, B.; Brose, M.S.; Elisei, R.; Habra, M.A.; Newbold, K.; Shah, M.H.; Hoff, A.O.; et al. Lenvatinib versus Placebo in Radioiodine-Refractory Thyroid Cancer. N. Engl. J. Med. 2015, 372, 621-630. [CrossRef] [PubMed]

84. Berdelou, A.; Borget, I.; Godbert, Y.; Nguyen, T.; Garcia, M.E.; Chougnet, C.N.; Ferru, A.; Buffet, C.; Chabre, O.; Huillard, O.; et al. Lenvatinib for the treatment of radioiodine-refractory thyroid cancer in real-life practice. Thyroid 2018. [CrossRef] [PubMed]

85. Locati, L.D.; Piovesan, A.; Durante, C.; Bregni, M.; Castagna, M.G.; Zovato, S.; Giusti, M.; Ibrahim, T.; Puxeddu, E.; Fedele, G.; et al. Real-world efficacy and safety of lenvatinib: Data from a compassionate use in the treatment of radioactive iodine-refractory differentiated thyroid cancer patients in Italy. Eur. J. Cancer 2019. [CrossRef] [PubMed]

86. Giani, C.; Valerio, L.; Bongiovanni, A.; Durante, C.; Grani, G.; Ibrahim, T.; Mariotti, S.; Massa, M.; Pani, F.; Pellegriti, G.; et al. Safety and Quality-of-Life Data from an Italian Expanded Access Program of Lenvatinib for Treatment of Thyroid Cancer. Thyroid 2020. [CrossRef]

87. Kim, S.Y.; Kim, S.M.; Kim, J.W.; Lee, I.J.; Jeon, T.J.; Chang, H.; Kim, B.W.; Lee, Y.S.; Chang, H.S.; Park, C.S. Survival With Lenvatinib for the Treatment of Progressive Anaplastic Thyroid Cancer: A Single-Center, Retrospective Analysis. Front. Endocrinol. $2020,11$. [CrossRef] [PubMed]

88. Takahashi, S.; Kiyota, N.; Yamazaki, T.; Chayahara, N.; Nakano, K.; INAGAKI, L.; Toda, K.; Enokida, T.; Minami, H.; Imamura, Y.; et al. Phase II study of lenvatinib in patients with differentiated, medullary, and anaplastic thyroid cancer: Final analysis results. J. Clin. Oncol. 2016, 34, 6088. [CrossRef]

89. Wells, S.A.; Robinson, B.G.; Gagel, R.F.; Dralle, H.; Fagin, J.A.; Santoro, M.; Baudin, E.; Elisei, R.; Jarzab, B.; Vasselli, J.R.; et al. Vandetanib in patients with locally advanced or metastatic medullary thyroid cancer: A randomized, double-blind phase III trial. J. Clin. Oncol. 2012, 30, 134-141. [CrossRef]

90. Fox, E.; Widemann, B.C.; Chuk, M.K.; Marcus, L.; Aikin, A.; Whitcomb, P.O.; Merino, M.J.; Lodish, M.; Dombi, E.; Steinberg, S.M.; et al. Vandetanib in children and adolescents with multiple endocrine neoplasia type $2 \mathrm{~b}$ associated medullary thyroid carcinoma. Clin. Cancer Res. 2013, 19, 4239-4248. [CrossRef] [PubMed]

91. Valerio, L.; Bottici, V.; Matrone, A.; Piaggi, P.; Viola, D.; Cappagli, V.; Agate, L.; Molinaro, E.; Ciampi, R.; Tacito, A.; et al. Medullary thyroid cancer treated with vandetanib: Predictors of a longer and durable response. Endocr. Relat. Cancer 2020, 27, 97-110. [CrossRef]

92. Ramos, H.E.; Hecht, F.; Berdelou, A.; Borget, I.; Leboulleux, S.; Baudin, E.; Schlumberger, M. Long-term follow-up and safety of vandetanib for advanced medullary thyroid cancer. Endocrine 2020, 71, 434-442. [CrossRef]

93. Elisei, R.; Schlumberger, M.J.; Müller, S.P.; Schöffski, P.; Brose, M.S.; Shah, M.H.; Licitra, L.; Jarzab, B.; Medvedev, V.; Kreissl, M.C.; et al. Cabozantinib in progressive medullary thyroid cancer. J. Clin. Oncol. 2013, 31, 3639-3646. [CrossRef]

94. Schlumberger, M.; Elisei, R.; Müller, S.; Schöffski, P.; Brose, M.; Shah, M.; Licitra, L.; Krajewska, J.; Kreissl, M.C.; Niederle, B.; et al. Overall survival analysis of EXAM, a phase III trial of cabozantinib in patients with radiographically progressive medullary thyroid carcinoma. Ann. Oncol. 2017, 28, 2813-2819. [CrossRef]

95. Drilon, A.; Laetsch, T.W.; Kummar, S.; DuBois, S.G.; Lassen, U.N.; Demetri, G.D.; Nathenson, M.; Doebele, R.C.; Farago, A.F.; Pappo, A.S.; et al. Efficacy of Larotrectinib in TRK Fusion-Positive Cancers in Adults and Children. N. Engl. J. Med. 2018, 378, 731-739. [CrossRef]

96. Tan, D.S.W.; Lassen, U.N.; Albert, C.M.; Kummar, S.; van Tilburg, C.; Dubois, S.G.; Geoerger, B.; Mascarenhas, L.; Federman, N.; Basu-Mallick, A.; et al. Larotrectinib efficacy and safety in TRK fusion cancer: An expanded clinical dataset showing consistency in an age and tumor agnostic approach. Ann. Oncol. 2018, 29, ix23. [CrossRef]

97. Hong, D.S.; DuBois, S.G.; Kummar, S.; Farago, A.F.; Albert, C.M.; Rohrberg, K.S.; van Tilburg, C.M.; Nagasubramanian, R.; Berlin, J.D.; Federman, N.; et al. Larotrectinib in patients with TRK fusion-positive solid tumours: A pooled analysis of three phase $1 / 2$ clinical trials. Lancet Oncol. 2020, 21, 531-540. [CrossRef]

98. Cabanillas, M.E.; Drilon, A.; Farago, A.F.; Brose, M.S.; McDermott, R.; Sohal, D.; Oh, D.-Y.; Almubarak, M.; Bauman, J.; Chu, E.; et al. 1916P Larotrectinib treatment of advanced TRK fusion thyroid cancer. Ann. Oncol. 2020, 31, S1086. [CrossRef]

99. Groussin, L.; Clerc, J.; Huillard, O. Larotrectinib-Enhanced Radioactive Iodine Uptake in Advanced Thyroid Cancer. N. Engl. J. Med. 2020, 383, 1686-1687. [CrossRef]

100. Doebele, R.C.; Drilon, A.; Paz-Ares, L.; Siena, S.; Shaw, A.T.; Farago, A.F.; Blakely, C.M.; Seto, T.; Cho, B.C.; Tosi, D.; et al. Entrectinib in patients with advanced or metastatic NTRK fusion-positive solid tumours: Integrated analysis of three phase 1-2 trials. Lancet Oncol. 2020, 21, 271-282. [CrossRef]

101. John, T.; Chiu, C.-H.; Cho, B.C.; Fakih, M.; Farago, A.F.; Demetri, G.D.; Goto, K.; Doebele, R.C.; Siena, S.; Drilon, A.; et al. 364O Intracranial efficacy of entrectinib in patients with NTRK fusion-positive solid tumours and baseline CNS metastases. Ann. Oncol. 2020, 31, S397-S398. [CrossRef]

102. Carlomagno, F.; Guida, T.; Anaganti, S.; Vecchio, G.; Fusco, A.; Ryan, A.J.; Billaud, M.; Santoro, M. Disease associated mutations at valine 804 in the RET receptor tyrosine kinase confer resistance to selective kinase inhibitors. Oncogene 2004, 23, 6056-6063. [CrossRef]

103. Wirth, L.J.; Sherman, E.; Robinson, B.; Solomon, B.; Kang, H.; Lorch, J.; Worden, F.; Brose, M.; Patel, J.; Leboulleux, S.; et al. Efficacy of Selpercatinib in RET -Altered Thyroid Cancers. N. Engl. J. Med. 2020, 383, 825-835. [CrossRef] 
104. Bradford, D.; Larkins, E.; Mushti, S.L.; Rodriguez, L.; Skinner, A.M.; Helms, W.S.; Price, L.S.L.; Fourie Zirkelbach, J.; Li, Y.; Liu, J.; et al. FDA Approval Summary: Selpercatinib for the Treatment of Lung and Thyroid cancers with RET Gene Mutations or Fusions. Clin. Cancer Res. 2020. [CrossRef] [PubMed]

105. Hernando, J.; Tarasova, V.; Hu, M.I.; Sherman, E.J.; Brose, M.S.; Robinson, B.; Tahara, M.; Wirth, L.J.; Sashegyi, A.; Soldatenkova, V.; et al. 1927TiP LIBRETTO-531: Selpercatinib in patients with treatment (Tx)-naïve RET-mutant medullary thyroid cancer (MTC). Ann. Oncol. 2020, 31, S1091. [CrossRef]

106. Subbiah, V.; Gainor, J.F.; Rahal, R.; Brubaker, J.D.; Kim, J.L.; Maynard, M.; Hu, W.; Cao, Q.; Sheets, M.P.; Wilson, D.; et al. Precision targeted therapy with BLU-667 for RET-driven cancers. Cancer Discov. 2018, 8, 836-849. [CrossRef] [PubMed]

107. Hu, M.; Subbiah, V.; Wirth, L.J.; Schuler, M.; Mansfield, A.S.; Brose, M.S.; Curigliano, G.; Leboulleux, S.; Zhu, V.W.; Keam, B.; et al. $1913 \mathrm{O}$ Results from the registrational phase I/II ARROW trial of pralsetinib (BLU-667) in patients (pts) with advanced RET mutation-positive medullary thyroid cancer (RET+ MTC). Ann. Oncol. 2020, 31, S1084. [CrossRef]

108. Brose, M.S.; Cabannilas, M.E.; Sherman, S.I.; Cohen, E.E.W.; Wirth, L.J.; Riehl, T.; Yue, H.; Sherman, E.J. Vemurafenib in patients with $\mathrm{BRAF}^{\mathrm{V} 600 \mathrm{E}}$-positive metastatic or unresectable papillary thyroid cancer refractory to radioactive iodine: A non-randomised, multicentre, open-label, phase 2 trial. Lancet Oncol. 2016, 17, 1272-1282. [CrossRef]

109. Hyman, D.M.; Puzanov, I.; Subbiah, V.; Faris, J.E.; Chau, I.; Blay, J.-Y.; Wolf, J.; Raje, N.S.; Diamond, E.L.; Hollebecque, A.; et al. Vemurafenib in Multiple Nonmelanoma Cancers with BRAF V600 Mutations. N. Engl. J. Med. 2015, 373, 726-736. [CrossRef]

110. Subbiah, V.; Cabanillas, M.E.; Kreitman, R.J.; Wainberg, Z.A.; Cho, J.Y.; Keam, B.; Schellens, J.H.M.; Soria, J.C.; Wen, P.Y.; Zielinski, C.; et al. Dabrafenib and trametinib treatment in patients with locally advanced or metastatic BRAF V600-mutant anaplastic thyroid cancer. J. Clin. Oncol. 2018, 36, 7-13. [CrossRef]

111. Keam, B.; Kreitman, R.J.; Wainberg, Z.A.; Cabanillas, M.E.; Cho, D.C.; Italiano, A.; Stein, A.; Cho, J.Y.; Schellens, J.H.M.; Wen, P.Y.; et al. Updated efficacy and safety data of dabrafenib (D) and trametinib (T) in patients (pts) with BRAF V600E-mutated anaplastic thyroid cancer (ATC). Ann. Oncol. 2018, 29, viii645-viii646. [CrossRef]

112. Shah, M.H.; Wei, L.; Wirth, L.J.; Daniels, G.A.; De Souza, J.A.; Timmers, C.D.; Sexton, J.L.; Beshara, M.; Nichols, D.; Snyder, N.; et al. Results of randomized phase II trial of dabrafenib versus dabrafenib plus trametinib in BRAF-mutated papillary thyroid carcinoma. J. Clin. Oncol. 2017, 35, 6022. [CrossRef]

113. Cabanillas, M.E.; Brose, M.S.; Holland, J.; Ferguson, K.C.; Sherman, S.I. A phase I study of cabozantinib (XL184) in patients with differentiated thyroid cancer. Thyroid 2014, 24, 1508-1514. [CrossRef] [PubMed]

114. Cabanillas, M.E.; De Souza, J.A.; Geyer, S.; Wirth, L.J.; Menefee, M.E.; Liu, S.V.; Shah, K.; Wright, J.; Shah, M.H. Cabozantinib as salvage therapy for patients with tyrosine kinase inhibitor-refractory differentiated thyroid cancer: Results of a multicenter phase II international thyroid oncology group trial. J. Clin. Oncol. 2017, 35, 3315-3321. [CrossRef] [PubMed]

115. Lin, Y.-S.; Qin, S.-K.; Li, Z.-Y.; Yang, H.; Fu, W.; Li, S.-H.; Chen, W.-X.; Gao, Z.-R.; Miao, W.-B.; Xu, H.-Q.; et al. LBA89 A randomized multicentered phase III study to evaluate apatinib in subjects with locally advanced or metastatic radioactive iodine-refractory differentiated thyroid cancer. Ann. Oncol. 2020. [CrossRef]

116. Sun, Y.; Niu, W.; Chi, Y.; Li, C.; Du, C.-X.; Li, S.; Wang, J.; Li, L.; Wang, F. Safety, pharmacokinetic, and antitumor activity of anlotinib, an oral multi-target tyrosine kinase inhibitor, in patients with advanced refractory solid tumors. J. Clin. Oncol. 2015, 33, e13586. [CrossRef]

117. Ruan, X.; Shi, X.; Dong, Q.; Yu, Y.; Hou, X.; Song, X.; Wei, X.; Chen, L.; Gao, M. Antitumor effects of anlotinib in thyroid cancer. Endocr. Relat. Cancer 2019, 26, 153-164. [CrossRef]

118. Chi, Y.; Gao, M.; Zhang, Y.; Shi, F.; Cheng, Y.; Guo, Z.; Ge, M.; Qin, J.; Zhang, J.; Li, Z.; et al. Anlotinib in locally advanced or metastatic radioiodine-refractory differentiated thyroid carcinoma: A randomized, double-blind, multicenter phase II trial. Ann. Oncol. 2020, 31, S1347. [CrossRef]

119. Handkiewicz-Junak, D.; Roskosz, J.; Hasse-Lazar, K.; Szpak-Ulczok, S.; Puch, Z.; Kukulska, A.; Olczyk, T.; Piela, A.; PaliczkaCieslik, E.; Jarzab, B. 13-cis-retinoic acid re-differentiation therapy and recombinant human thyrotropin-aided radioiodine treatment of non-Functional metastatic thyroid cancer: A single-center, 53-patient phase 2 study. Thyroid Res. 2009, 2, 8. [CrossRef] [PubMed]

120. Liu, Y.Y.; Van Der Pluijm, G.; Karperien, M.; Stokkel, M.P.M.; Pereira, A.M.; Morreau, J.; Kievit, J.; Romijn, J.A.; Smit, J.W.A. Lithium as adjuvant to radioiodine therapy in differentiated thyroid carcinoma: Clinical and in vitro studies. Clin. Endocrinol. 2006, 64, 617-624. [CrossRef] [PubMed]

121. Ho, A.L.; Grewal, R.K.; Leboeuf, R.; Sherman, E.J.; Pfister, D.G.; Deandreis, D.; Pentlow, K.S.; Zanzonico, P.B.; Haque, S.; Gavane, S.; et al. Selumetinib-Enhanced Radioiodine Uptake in Advanced Thyroid Cancer. N. England J. Med. 2013, 368, 623-632. [CrossRef] [PubMed]

122. Ho, A.; Dedecjus, M.; Wirth, L.J.; Tuttle, R.; Tennaval, J.S.K.; Carroll, D.; Hovey, T.; Thakre, B.F.J. ASTRA: A phase III, randomized, placebo-controlled study evaluating complete remission rate (CRR) with short-course selumetinib plus adjuvant radioactive iodine (RAI) in patients (pts) with differentiated thyroid cancer (DTC). In Proceedings of the 88th Annual Meeting of the American Thyroid Association, Washington, DC, USA, 3-7 October 2018. Abstract short call oral 8, 2018.

123. Dunn, L.A.; Sherman, E.J.; Baxi, S.S.; Tchekmedyian, V.; Grewal, R.K.; Larson, S.M.; Pentlow, K.S.; Haque, S.; Tuttle, R.M.; Sabra, M.M.; et al. Vemurafenib redifferentiation of BRAF mutant, Rai-refractory thyroid cancers. J. Clin. Endocrinol. Metab. 2019, 104, 1417-1428. [CrossRef] [PubMed] 
124. Rothenberg, S.M.; McFadden, D.G.; Palmer, E.L.; Daniels, G.H.; Wirth, L.J. Redifferentiation of iodine-refractory BRAF V600Emutant metastatic papillary thyroid cancer with dabrafenib. Clin. Cancer Res. 2015, 21, 1028-1035. [CrossRef] [PubMed]

125. Jaber, T.; Waguespack, S.G.; Cabanillas, M.E.; Elbanan, M.; Vu, T.; Dadu, R.; Sherman, S.I.; Amit, M.; Santos, E.B.; Zafereo, M.; et al. Targeted therapy in advanced thyroid cancer to resensitize tumors to radioactive iodine. J. Clin. Endocrinol. Metab. 2018, 103, 3698-3705. [CrossRef]

126. De Falco, V.; Buonocore, P.; Muthu, M.; Torregrossa, L.; Basolo, F.; Billaud, M.; Gozgit, J.M.; Carlomagno, F.; Santoro, M. Ponatinib (AP24534) is a novel potent inhibitor of oncogenic RET mutants associated with thyroid cancer. J. Clin. Endocrinol. Metab. 2013, 98. [CrossRef]

127. Mologni, L.; Redaelli, S.; Morandi, A.; Plaza-Menacho, I.; Gambacorti-Passerini, C. Ponatinib is a potent inhibitor of wild-type and drug-resistant gatekeeper mutant RET kinase. Mol. Cell. Endocrinol. 2013, 377, 1-6. [CrossRef]

128. Drilon, A.E.; Zhai, D.; Rogers, E.; Deng, W.; Zhang, X.; Ung, J.; Lee, D.; Rodon, L.; Graber, A.; Zimmerman, Z.F.; et al. The next-generation RET inhibitor TPX-0046 is active in drug-resistant and naïve RET-driven cancer models. J. Clin. Oncol. 2020, 38, 3616. [CrossRef]

129. Mehnert, J.M.; Varga, A.; Brose, M.S.; Aggarwal, R.R.; Lin, C.C.; Prawira, A.; De Braud, F.; Tamura, K.; Doi, T.; Piha-Paul, S.A.; et al. Safety and antitumor activity of the anti-PD-1 antibody pembrolizumab in patients with advanced, PD-L1-positive papillary or follicular thyroid cancer. BMC Cancer 2019, 19. [CrossRef] [PubMed]

130. Capdevila, J.; Wirth, L.J.; Ernst, T.; Aix, S.P.; Lin, C.C.; Ramlau, R.; Butler, M.O.; Delord, J.P.; Gelderblom, H.; Ascierto, P.A.; et al. PD-1 blockade in anaplastic thyroid carcinoma. J. Clin. Oncol. 2020, 38, 2620-2627. [CrossRef] [PubMed]

131. Chintakuntlawar, A.V.; Yin, J.; Foote, R.L.; Kasperbauer, J.L.; Rivera, M.; Asmus, E.; Garces, N.I.; Janus, J.R.; Liu, M.; Ma, D.J.; et al. A Phase 2 Study of Pembrolizumab Combined with Chemoradiotherapy as Initial Treatment for Anaplastic Thyroid Cancer. Thyroid 2019, 29, 1615-1622. [CrossRef] [PubMed]

132. Sherman, E.J.; Tsai, C.J.; Zhi, W.I.; Fetten, J.V.; Wu, V.; Ho, A.L.; Riaz, N.; Pfister, D.G.; Lee, N.Y. Pilot study combining PD-L1 antibody durvalumab (D) with CTLA-4 antibody tremelimumab (T) and stereotactic body radiotherapy (SBRT) to treat metastatic anaplastic thyroid cancer (ATC). J. Clin. Oncol. 2019, 37, 6088. [CrossRef]

133. Dierks, C.; Seufert, J.; Ruf, J.; Duyster, J.; Thomusch, O.; Miething, C.; Zielke, A. 1915P The lenvatinib/pembrolizumab combination induces long lasting and complete responses in patients with metastatic anaplastic or poorly differentiated thyroid carcinoma: Results from a retrospective study and first results from the prospective phase I. Ann. Oncol. 2020, 31, S1085. [CrossRef]

134. Resteghini, C.; Cavalieri, S.; Galbiati, D.; Granata, R.; Alfieri, S.; Bergamini, C.; Bossi, P.; Licitra, L.; Locati, L.D. Management of tyrosine kinase inhibitors (TKI) side effects in differentiated and medullary thyroid cancer patients. Best Pract. Res. Clin. Endocrinol. Metab. 2017, 31, 349-361. [CrossRef]

135. Wirth, L.J.; Tahara, M.; Robinson, B.; Francis, S.; Brose, M.S.; Habra, M.A.; Newbold, K.; Kiyota, N.; Dutcus, C.E.; Mathias, E.; et al. Treatment-emergent hypertension and efficacy in the phase 3 Study of (E7080) lenvatinib in differentiated cancer of the thyroid (SELECT). Cancer 2018, 124, 2365-2372. [CrossRef] [PubMed]

136. Granito, A.; Marinelli, S.; Negrini, G.; Menetti, S.; Benevento, F.; Bolondi, L. Prognostic significance of adverse events in patients with hepatocellular carcinoma treated with sorafenib. Ther. Adv. Gastroenterol. 2016, 9, 240-249. [CrossRef]

137. Kucharz, J.; Dumnicka, P.; Kusnierz-Cabala, B.; Demkow, T.; Wiechno, P. The correlation between the incidence of adverse events and progression-free survival in patients treated with cabozantinib for metastatic renal cell carcinoma (mRCC). Med Oncol. 2019, 36. [CrossRef] [PubMed]

138. Cappagli, V.; Moriconi, D.; Bonadio, A.G.; Giannese, D.; La Manna, G.; Egidi, M.F.; Comai, G.; Vischini, G.; Bottici, V.; Elisei, R.; et al. Proteinuria is a late-onset adverse event in patients treated with cabozantinib. J. Endocrinol. Investig. 2021, 44, 95-103. [CrossRef]

139. Tahara, M.; Schlumberger, M.; Elisei, R.; Habra, M.A.; Kiyota, N.; Paschke, R.; Dutcus, C.E.; Hihara, T.; McGrath, S.; Matijevic, M.; et al. Exploratory analysis of biomarkers associated with clinical outcomes from the study of lenvatinib in differentiated cancer of the thyroid. Eur. J. Cancer 2017, 75, 213-221. [CrossRef]

140. Tiedje, V.; Ting, S.; Walter, R.F.; Herold, T.; Worm, K.; Badziong, J.; Zwanziger, D.; Schmid, K.W.; Führer, D. Prognostic markers and response to vandetanib therapy in sporadic medullary thyroid cancer patients. Eur. J. Endocrinol. 2016, 175, 173-180. [CrossRef]

141. Fugazzola, L.; Muzza, M.; Pogliaghi, G.; Vitale, M. Intratumoral genetic heterogeneity in papillary thyroid cancer: Occurrence and clinical significance. Cancers 2020, 12, 383. [CrossRef]

142. Bedard, P.L.; Hansen, A.R.; Ratain, M.J.; Siu, L.L. Tumour heterogeneity in the clinic. Nature 2013, 501, 355-364. [CrossRef]

143. Hass, R.; von der Ohe, J.; Ungefroren, H. Impact of the tumor microenvironment on tumor heterogeneity and consequences for cancer cell plasticity and stemness. Cancers 2020, 12, 3716. [CrossRef] [PubMed]

144. Oellerich, M.; Schütz, E.; Beck, J.; Kanzow, P.; Plowman, P.N.; Weiss, G.J.; Walson, P.D. Using circulating cell-free DNA to monitor personalized cancer therapy. Crit. Rev. Clin. Lab. Sci. 2017, 54, 205-218. [CrossRef] 